\title{
AMPLIACIÓN DE LAS LUCES DE 14 PASOS SUPERIORES CONTINUOS POSTESADOS PARA CONSEGUIR EL ENSANCHAMIENTO A SEIS CARRILES DE LA AUTOPISTA A-7 BARCELONA-LA JUNQUERA. TRAMO: HOSTALRIC-MAÇANET
}

\author{
(ENLARGING OF THE SPANS OF 14 CONTINUIOUS POST-STRESSED OVERPASSES IN \\ ORDER TO EXTEND THE A-7 BARCELONA - LA JUNQUERA HIGHWAY TO SIX LANES)
}

Julio Martínez Calzón, Dr. Ingeniero de Caminos

MC-2 Estudio de Ingeniería. Madrid

ESPAÑA
Fecha de recepción: 14 - VII - 94 $524-7$

\section{RESUMEN}

Se describe un procedimiento constructivo de gran sencillez y posibilidades para el desplazamiento de pilas de puentes, en los cuales se requiere una ampliación de sus luces para favorecer el tráfico en las vías inferiores a los mismos.

El método se basa en disponer paralelamente a la estructura un sistema de dos vigas metálicas - a modo de paribuelas - que recogen las reacciones permanentes de las pilas antiguas y las trasladan hasta las nuevas. Para lograr la transferencia de cargas por contacto entre el puente antiguo y las nuevas vigas se dispone un pretensado transversal de cosido de ambos sistemas.

En la estructura con las nuevas pilas el conjunto formado por el antiguo tablero y las dos vigas incorporadas resisten combinadamente las acciones provocadas por las sobrecargas de uso.

Además de la solución tipo, se exponen interesantes variantes para casos especiales de puentes curvos, esviados, dobles, etc.

\section{SUMMARY}

The article describes a simple construction process which provides the possibility of displacement of bridge piers when enlarging of spans is required to meet the demands of traffic under the bridge.

The method is based on setting up a stretcher-like system consisting of two steel girders parallel to the structure. The girders gather the permanent forces of the old piers and transfer them to the new ones. In order to achieve the load transference from the old bridge to the new girders, a transverse prestressed web is used in both systems.

In the new pier structure, the old deck and the two incorporated girders jointly resist the actions of the service overloads.

Beside the pattern solution, the article describes some interesting variations for special cases suche as curved, biaxially bent, double bridges, etc. 
En muchas ocasiones la dimensión reducida de una obra de ingeniería puede alcanzar niveles de interés técnico y estructural tan atractivos o más, si cabe, desde un punto de vista profundo, como los logrados con espectaculares obras de grandes dimensiones que no hacen sino reiterar otras obras ya bien conocidas. Creo que la solución adoptada para la realización del encargo solicitado al autor de este artículo por don Francisco Criado, Ingeniero de Caminos, Subdirector General de Carreteras actualmente, pero entonces Jefe de la Agrupación de Proyectos y Obras de Autopistas Concesionaria Española (ACESA); y que culminó en la realización de la serie de ampliaciones de las luces de 14 pasos superiores de hormigón pretensado sobre la Autopista A-7, Barcelona-La Junquera, se encuadra de forma realmente perfecta en tal afirmación.

La Autopista A-7 fue proyectada y construida con una sección de cuatro carriles, dos por calzada, sin posibilidad de ampliación a seis carriles, tres por calzada, por la mediana. El crecimiento experimentado por el tráfico de esta vía, que funciona como una arteria fundamental en el disfrute de la bella región del Ampurdán por Barcelona capital, como lugar de vacación y descanso del fin de semana, así como del importante crecimiento de la incidencia del turismo europeo hacia toda la costa levantina y de la gran penetración de mercancías que recoge, motivó que esta ampliación se hiciera necesaria, tanto desde el punto de vista de capacidad como de seguridad.
Aunque en forma estricta, disponiendo defensas rígidas en los bordes junto a las pilas, y llevando a cabo operaciones de señalización y ajuste adecuados, se podrían haber encajado los tres carriles en los vanos de las obras de fábrica existentes, el buen criterio señalaba que dicha solución daría lugar a unas condiciones permanentes psíquica y realmente problemáticas, por la estrechez y angostura sistemática que percibiría el usuario, lo cual inmediatamente trasciende en reducción de capacidad e incremento de la inseguridad.

La Dirección Técnica de la Concesionaria de la Autopista consideró por todo ello obligado plantear la remodelación de todos aquellos pasos superiores que no permitían, por sus luces, incluir los arcenes y distancias usuales a los elementos verticales y defensas de las pilas. Esta remodelación se basaba en ampliar los vanos interiores de dichas obras de fábrica, reduciendo las luces de los exteriores mediante una traslación de las pilas intermedias.

A tal efecto en 1988 ACESA solicitó a diferentes técnicos soluciones para resolver este problema de la forma más favorable posible.

Cuando, en 1989, se me planteó este encargo ya existían algunas versiones basadas en soluciones atirantadas con pilas sobre el nivel de los pasos, ménsulas laterales de grandes dimensiones, etc., pero que claramente resultaban poco satisfactorias desde diversos puntos de vista: coste, procesos

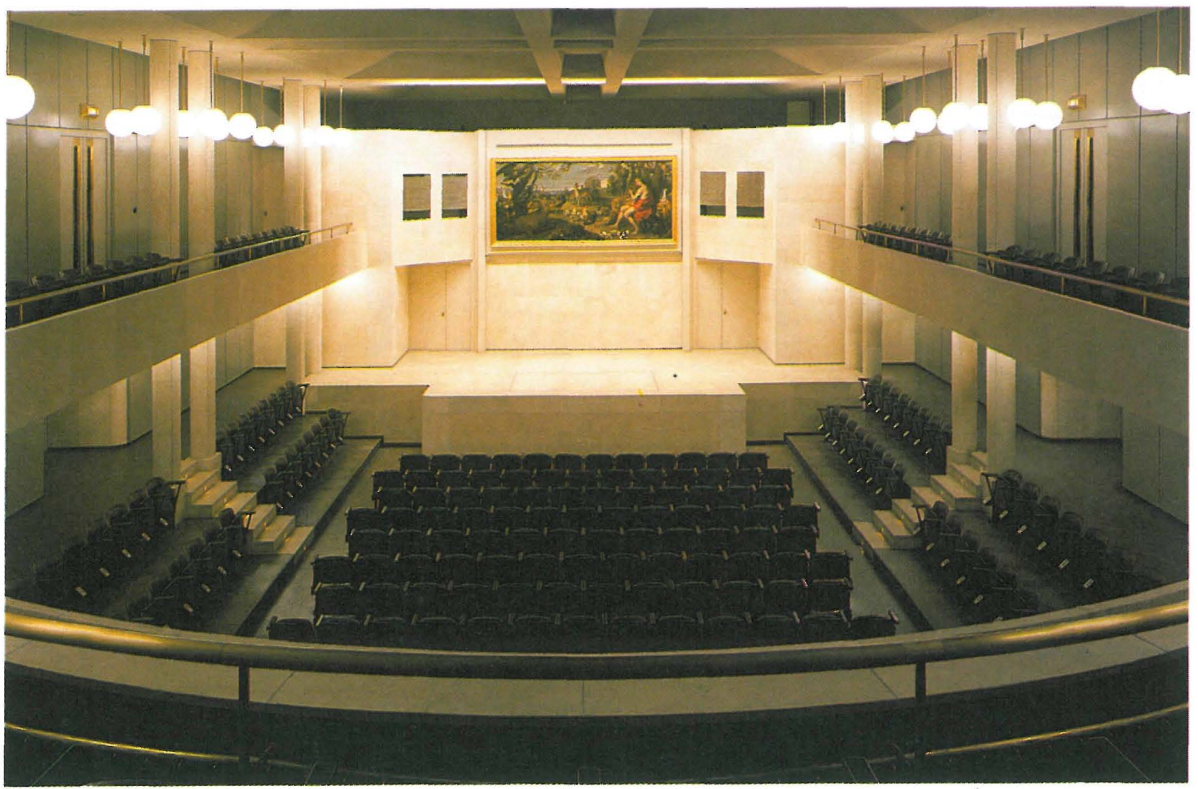

Sala villanueva del Museo del Prado. 


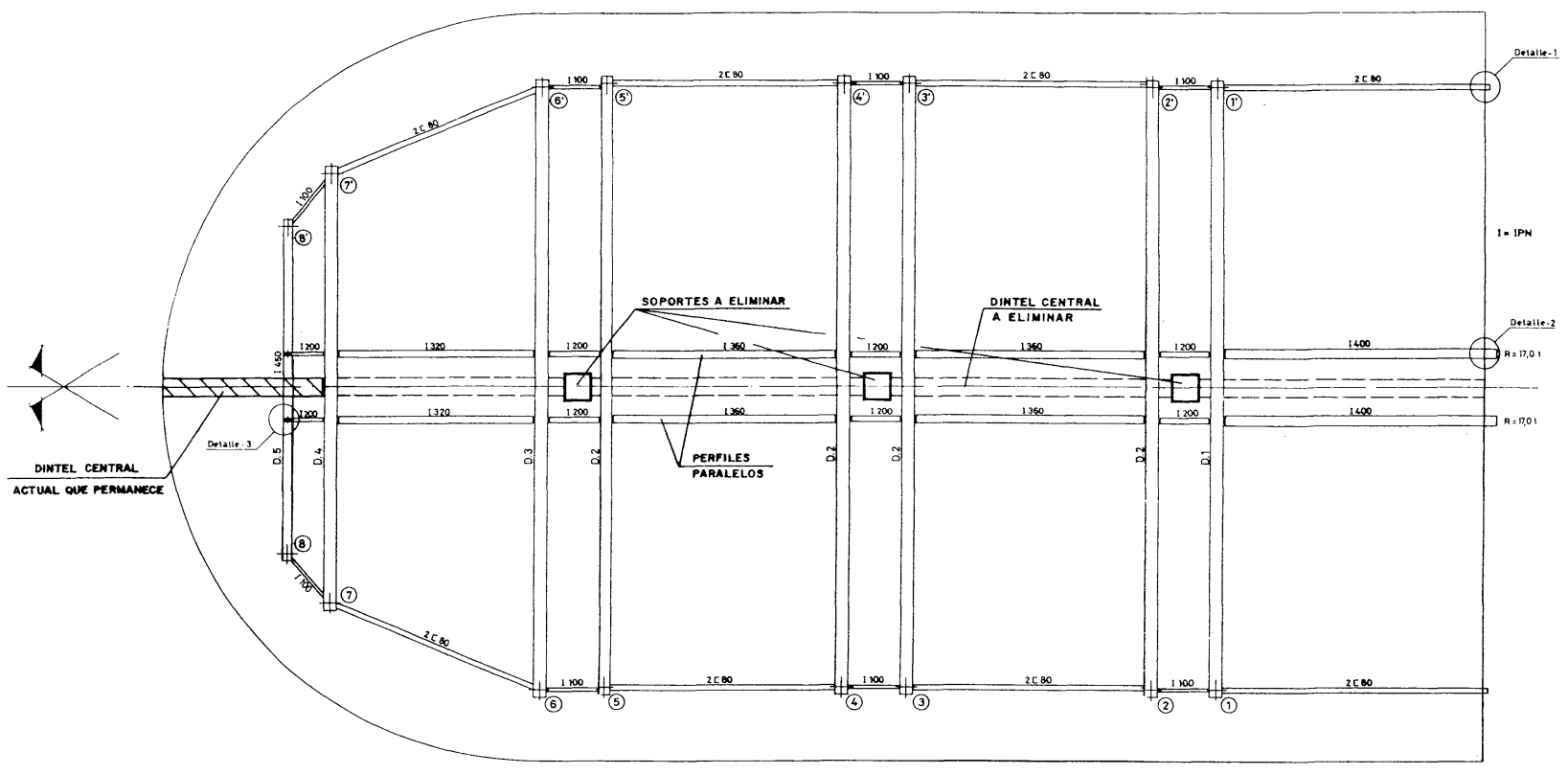

NUEVA ESTRUCTURA DE SUSTENTACION SALA VILLANUEVA

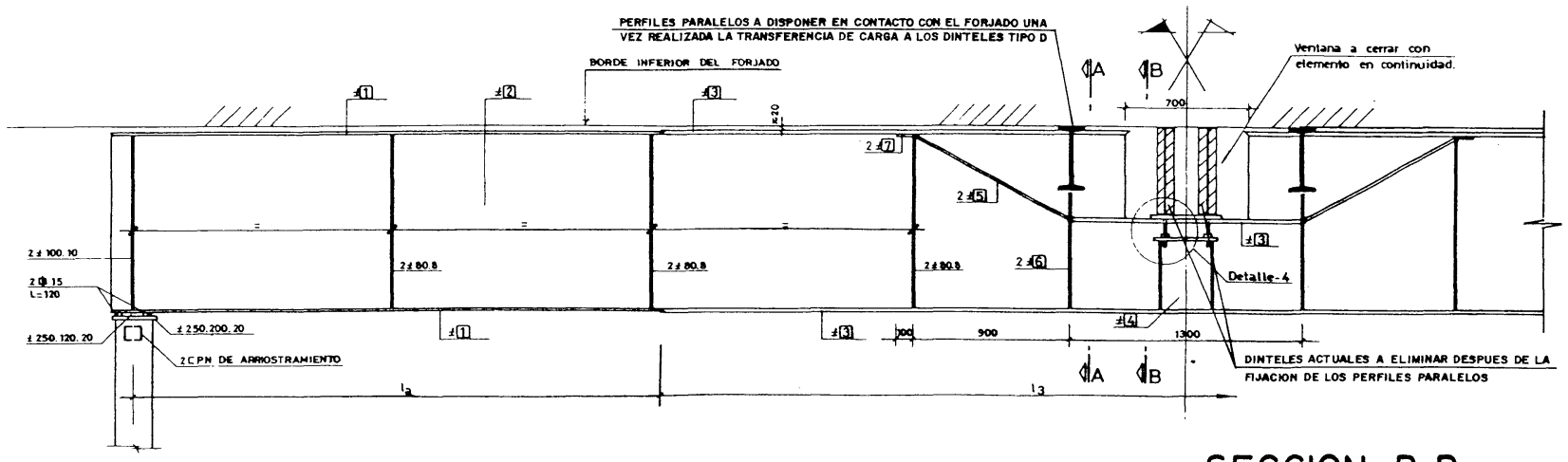

DINTEL TIPO (D.1-D.2-D.3)
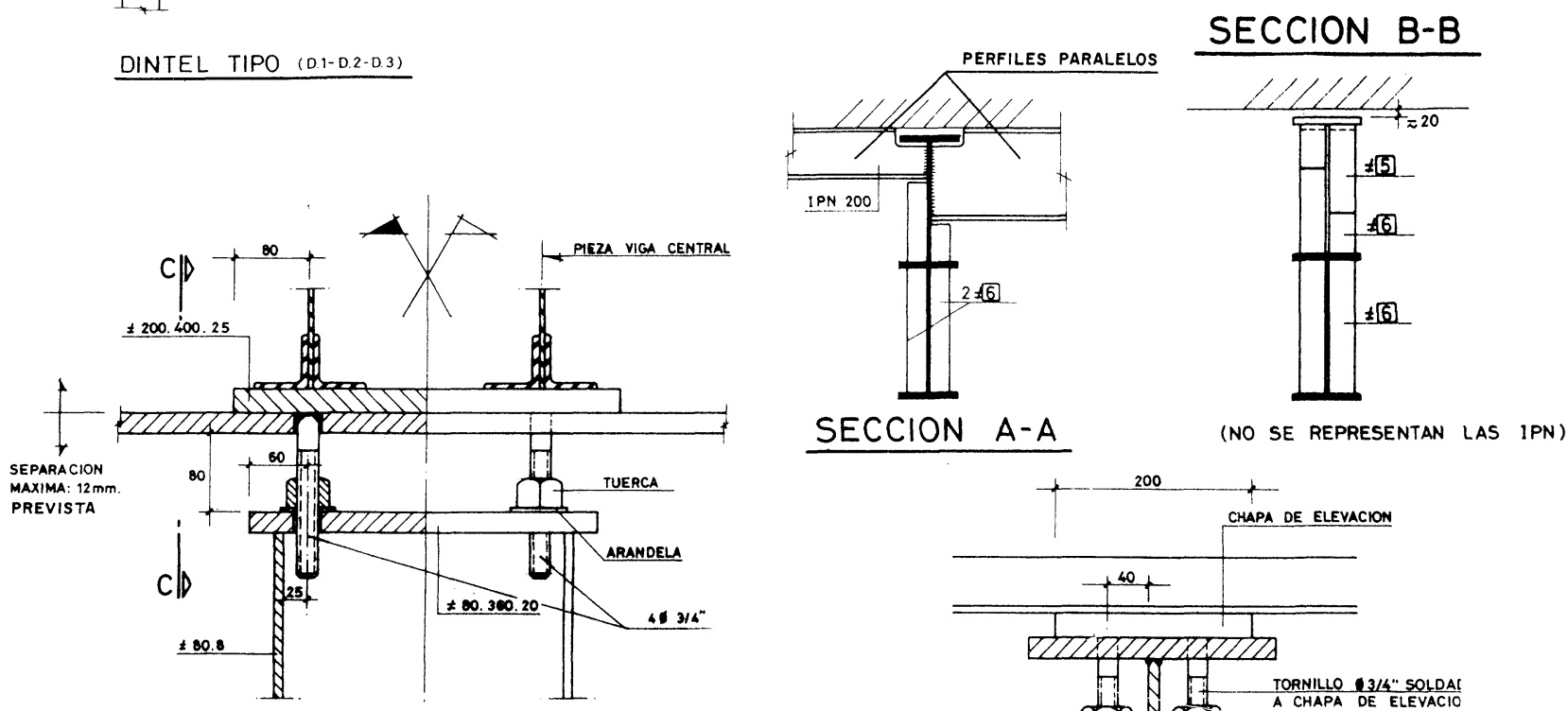

SECCION A-A (NO SE REPRESENTAN LAS IPN)

DETALLE - 4 MECANISMO DE TRANSFERENCIA DE CARGA ENTRE DINTELES ACTUALES $Y$ NUEVOS TIPO D.

Fig. 1. Esquema de la solución de transferencia para eliminar los soportes centrales de apoyo de la Sala Villanueva del Museo del Prado.

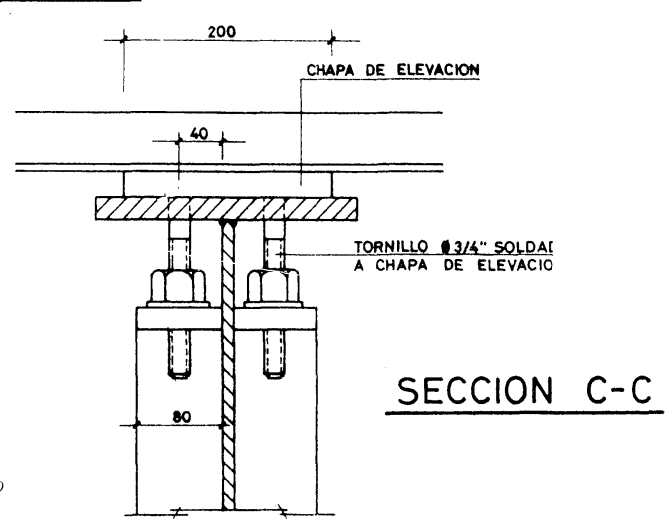


constructivos y tiempo de realización, y también, en gran medida, estéticos y de imagen de la Autopista.

La importante presencia de esta vía en el ámbito y patrimonio catalanes por lo que supone de prestigio para toda la región, puerta de entrada desde Francia y gran empleo por toda la sociedad de Barcelona y Gerona fundamentalmente, implicaba una decisión muy comprometida aceptar soluciones poco afortunadas en el aspecto estético.

Cuando me hice cargo del trabajo, planteé inicialmente soluciones basadas en pretensados externos adicionales, pero pronto fueron desechadas, no sólo porque su incidencia estética sería también muy dura, sino porque debido a la gran esbeltez motivada por los cantos estrictos de las estructuras a ampliar, las componentes horizontales requeridas para el mantenimiento y traslado de las reacciones eran extraordinariamente elevadas y difíciles de aceptar por el sistema estructural existente.

Entonces y como fruto de la experiencia propia anterior en la eliminación de soportes de dos edificios singulares, y fundamentalmente en el caso de la realización de la Sala de Conferencias Juan de Villanueva del Museo del Prado de Madrid, realizada bajo la gran sala de Velázquez, en la cual se ubican los famosos cuadros de "Las lanzas", "La Fragua de Vulcano", etc., consideré una solución variante singular. En aquella ocasión y como colaboración para el arquitecto José María García de Paredes, planteé la eliminación de toda una hilera de soportes centrales inferiores, sin alterar ni afectar el costoso pavimento de dicha sala, para crear el gran espacio inferior actual, en la forma que reflejan los gráficos y fotos adjuntos (Fig. 1) En base a los mismos principios allí empleados podía plantearse una solución que resolviera el problema en forma adecuada y con una presencia estética que incluso podría ofrecer una nueva personalidad a la Autopista.

En líneas generales, la solución podría denominarse de "tipología de angarillos o parihuelas", consiste en disponer una estructura combinada formada por la existente y una pareja de vigas metálicas de canto muy reducido, que se sitúan paralelamente a la estructura actual y por debajo de sus voladizos, y en interacción con aquélla. Aunque en principio se pensó disponer estas piezas como mixtas, conectando su parte metálica con el hormigón de la estructura, un análisis más preciso decantó la solución por la variante de piezas metálicas simples.
Esta pareja de barras, como paralelas de un gimnasta, permiten el apoyo de sus manos, los puntos coincidentes con la sustentación en las pilas antiguas, y la transferencia de todas sus cargas permanentes hacia los apoyos en las nuevas pilas. Posteriormente, el conjunto de ambas estructuras, nueva y antigua, adecuadamente unidas -y de aquí la denominación de estructura compuesta - trabajan conjuntamente en la resistencia frente a las sobrecargas de uso.

Toda la solución es, lógicamente, fruto de las posibilidades que las técnicas de nuestro tiempo permiten: perforación ajustada y precisa de grandes piezas de hormigón, pretensados cortos, control de gatos, etc.

Seguidamente se lleva a cabo una exposición pormenorizada del procedimiento utilizado que, más allá de la solución estricta para resolver el problema particular de este caso -incluidas las soluciones variante de los puentes singulares curvos, esviados, dobles y pilas de formas diferentes-, responde a una solución genérica y amplia para resolver gran número de problemas y situaciones que las circunstancias cada vez más complejas de nuestra sociedad reclaman en cuanto a cambios, transformaciones, rehabilitaciones, etc., y de las cuales la antes citada del Museo del Prado es una clara muestra retroactiva.

Otra circunstancia que parece oportuno señalar, y la posterior descripción pondrá de manifiesto, es el extremado grado de seguridad que este tipo de operaciones procura, al efectuarse todo el trabajo sin interferencias prácticas con la Autopista y el enorme tráfico que soporta; y la garantía que ofrece el proceso de puesta en carga y transferencia sin llevarse a cabo la eliminación de los apoyos antiguos hasta el final de la prueba de carga de la nueva estructura, y que en todo momento permite el retorno a la situación inicial, si se observase cualquier fallo o vicio oculto.

Todo esto unido al coste apropiado y unos plazos reducidos de ejecución en conjunto con la calidad estética de la solución alcanzada, hacen que pueda considerarse el resultado como de gran calidad y elegancia.

\section{Planteamiento general}

El planteamiento base consistía sencillamente en lograr la ampliación de las luces intermedias de una serie de vigas continuas de cuatro vanos de 12,50- 


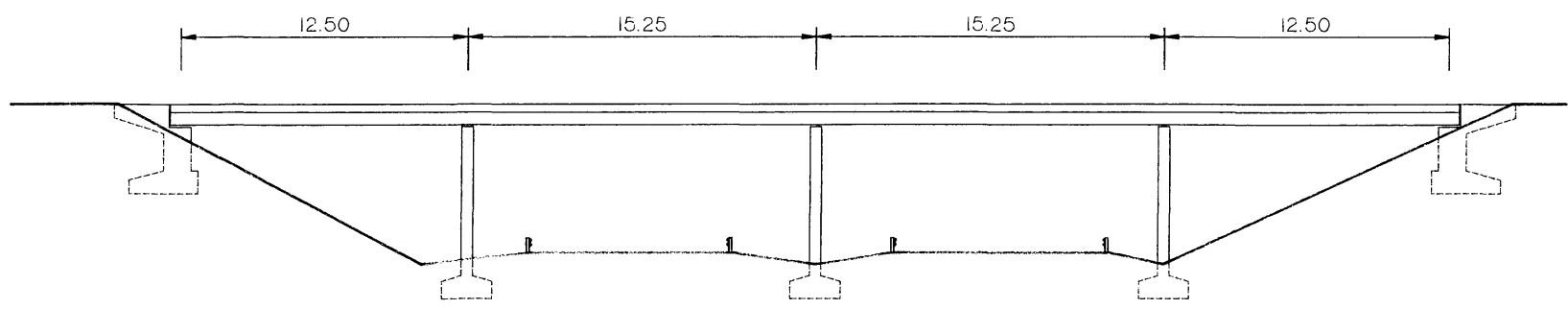

SITUACION INICIAL

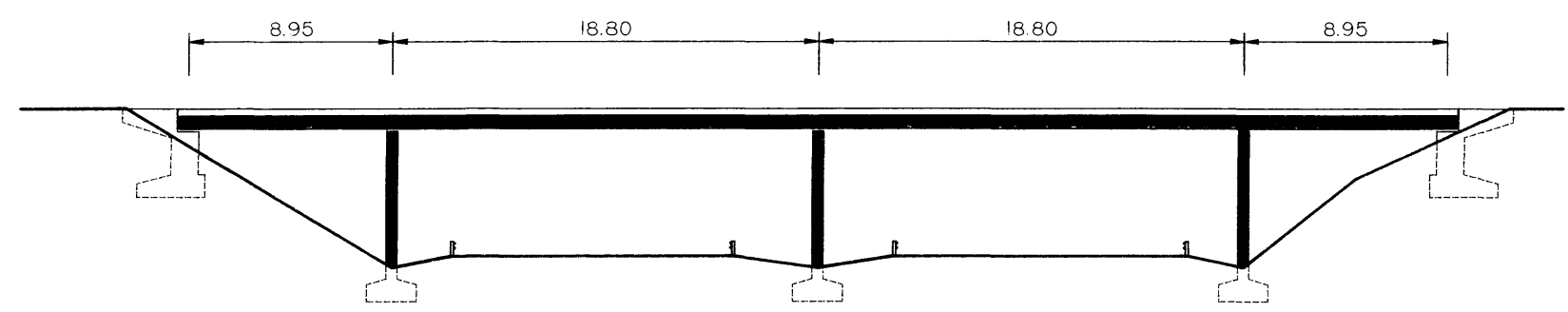

SITUACION FINAL

Fig. 2. Disposición de pasos típicos.

15,25-15,25-12,50 m hasta alcanzar los 18,80 m, necesarios para la inclusión de un tercer carril en cada sentido, y sus correspondientes arcenes. Es decir, un incremento de $3,55 \mathrm{~m}$, en cada vano de $15,25 \mathrm{~m}$, lo cual representa un 23,5 por ciento de su luz (Fig. 2)

Los objetivos del proceso se centraban en tres aspectos fundamentalmente:

1. Rapidez y garantía de la operación sin alterar en ningún momento los tráficos viarios, tanto de la Autopista como de los pasos superiores.

2. Mantenimiento de los ajustados gálibos existentes y logro de un aspecto estético final de la mayor dignidad.

3. Costes y plazos de ejecución mínimos.

Las elevadas esbelteces de las nuevas luces a lograr con cantos situados entre L/25 y L/28,5, con descuelgues bajo los voladizos de la losa del orden de $\mathrm{L} / 46$ a L/54, constituían la dificultad fundamental; a la cual se añadía el afinado proyecto con el cual fueron constituidos los pasos, que apenas permitían márgenes de maniobra resistentes para lograr una solución apropiada, máxime cuando se requirió que las nuevas estructuras ampliadas debían ser perfectamente válidas para adecuarse a la actual normativa de Acciones a Considerar en los puentes de carretera, y no a la existente en el momento de la ejecución de las obras, y con la cual se habían realizado los referidos proyectos, que exigían cargas menores.

El método empleado se basa, esencialmente, en incorporar a ambos lados de las losas aligeradas de hormigón pretensado, y situadas bajo los voladizos de las mismas, dos vigas cajón metálicas romboidales de canto muy estricto (Fig.3), que se apoyaban en la nueva secuencia de pilas, ligeramente ensanchadas respecto a las actuales. Estas vigas, realizadas en acero estructural resistente a la corrosión, tipo CORTEN, permitían llevar a cabo dos procesos básicos:

1. Recoger de manera autónoma -es decir, totalmente desvinculadas de la estructura de hormigón existente- las reacciones debidas a las cargas permanentes en las pilas a demoler y trasladarlas a la nueva secuencia de pilas, sin alterar en lo más mínimo la deformada actual del tablero de hormigón y, por consiguiente, sin cambio ninguno de los esfuerzos existentes en el mismo. 


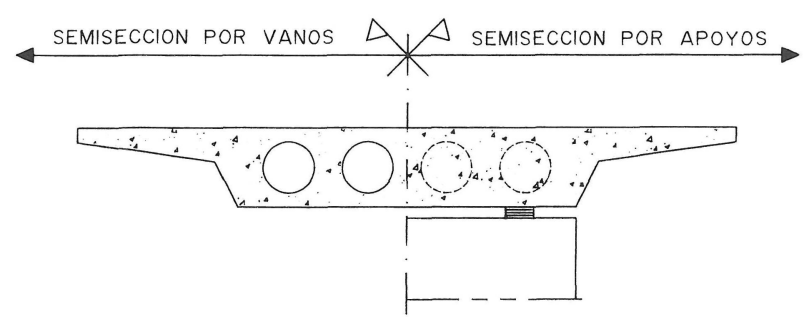

PILA EXISTENTE
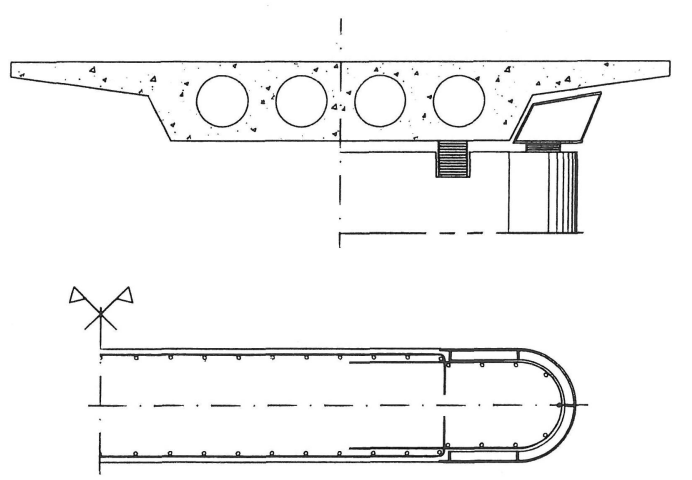

PILA NUEVA

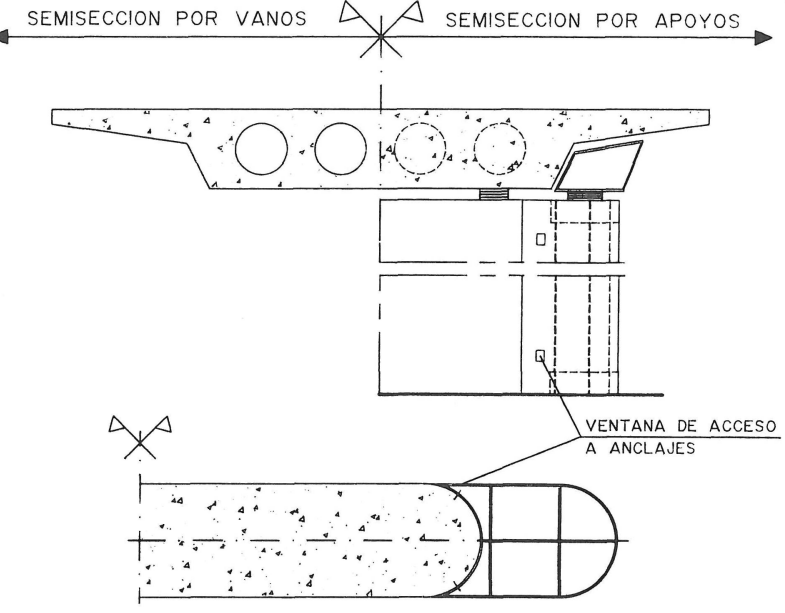

PILA MODIFICADA

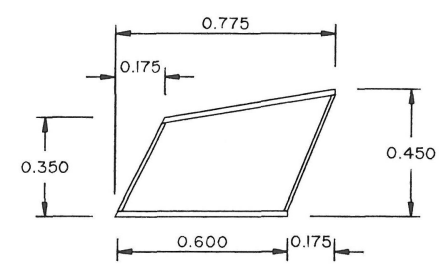

SECCION TIPO DE VIGAS

Fig. 3. Disposición y secciones transversales.

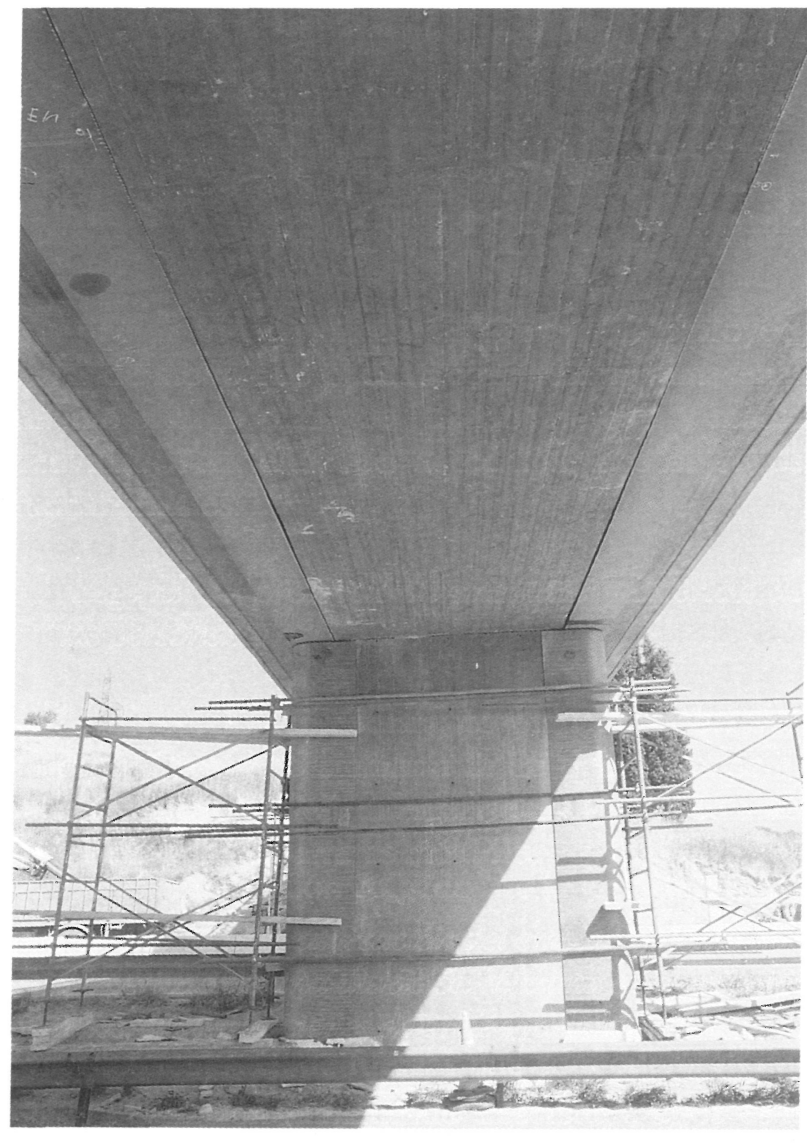

Disposición de vigas metálicas y' ampliación de pilas.
Las deformaciones y movimientos de las vigas metálicas se producen totalmente ajenas a la estructura de hormigón y quedan, por tanto, exteriores a la misma, siendo estrictamente compensadas mediante la disposición de adecuadas contraflechas de ejecución (Fig. 4).

Se emplea un concepto muy semejante al que se produce en el pretensado de estructuras: los alargamientos de las armaduras activas no inciden en el sistema, y son compensados por el corte de los mismos tras el tesado.

2. Colaborar en forma conjunta con la estructura actual, en la resistencia frente a las sobrecargas de uso, aprovechando las vinculaciones que se llevan a cabo entre ambos sistemas durante el proceso de ampliación (Fig. 5).

Para optimizar esta segunda condición, en la idea de lograr la mayor igualdad posible entre las respuestas del sistema de hormigón y de las vigas metálicas frente a las citadas sobrecargas de la Instrucción actual, el apoyo de la estructura de hormigón en las pilas nuevas se lleva a cabo mediante apoyos elásticos, cuyos coeficientes de muelle se deducen para lograr que el 


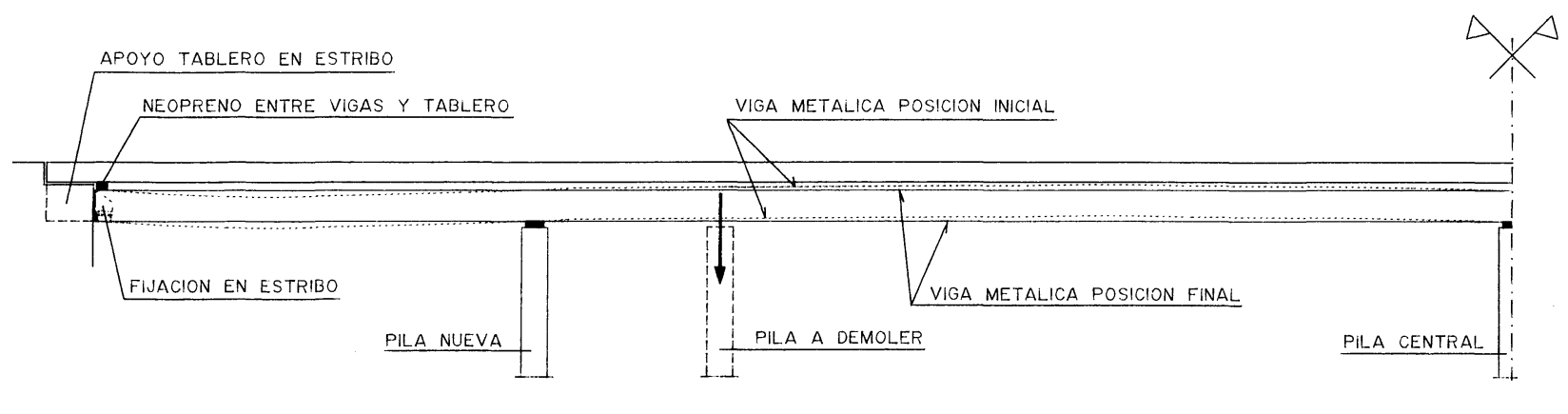

Fig. 4. Transferencia de reacciones de pilas antiguas a nuevas.

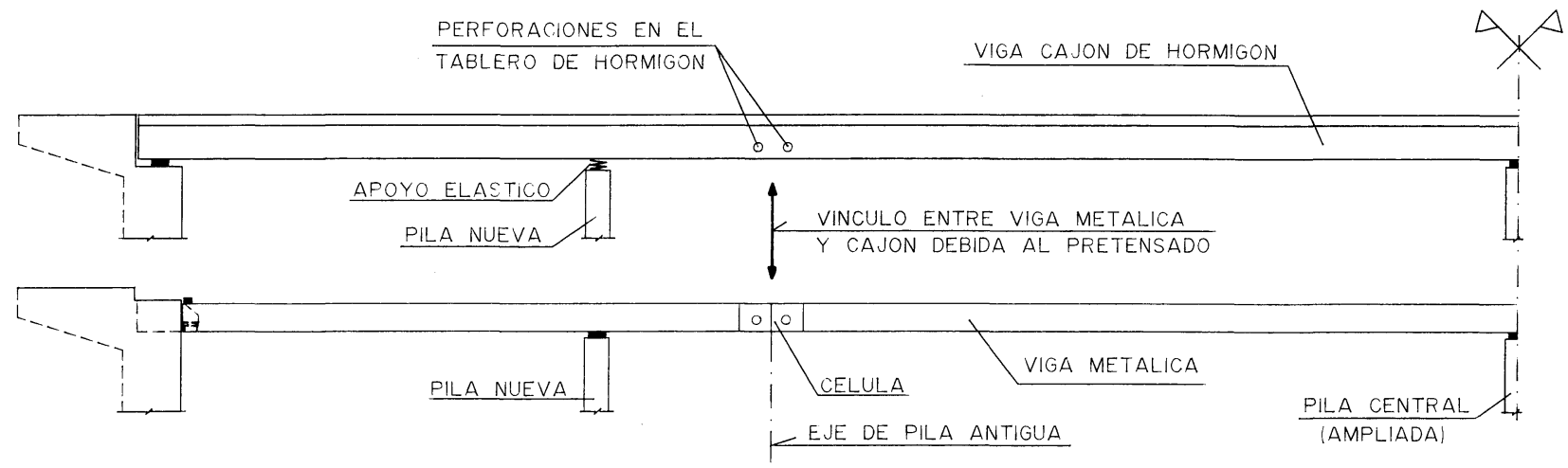

ALZADO IDEAL

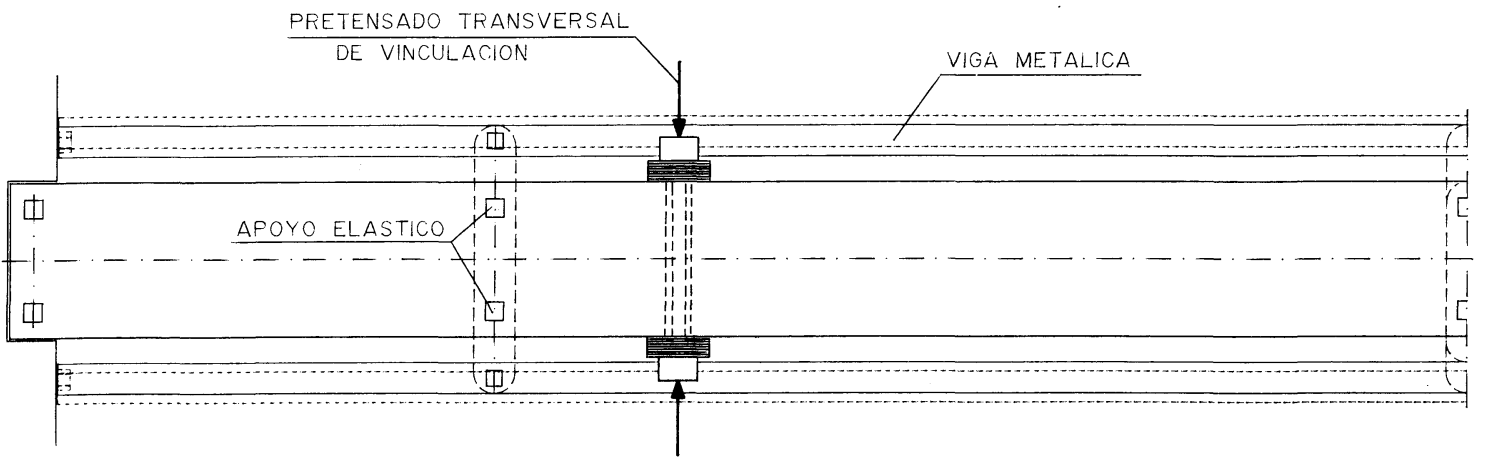

PLANTA

Fig. 5. Colaboración conjunta final de vigas metálicas y tablero de bormigón.

pico de la envolvente de momentos negativos mayorados en las secciones del tablero de hormigón situadas sobre dichas pilas no superen los momentos últimos de las mencionadas secciones. Estos momentos últimos eran relativa- mente pequeños por el hecho de que, ai estar las secciones bastante desplazadas respecto a los antiguos apoyos, la excentricidad del pretensado existente en las mismas presentaba valores reducidos. 


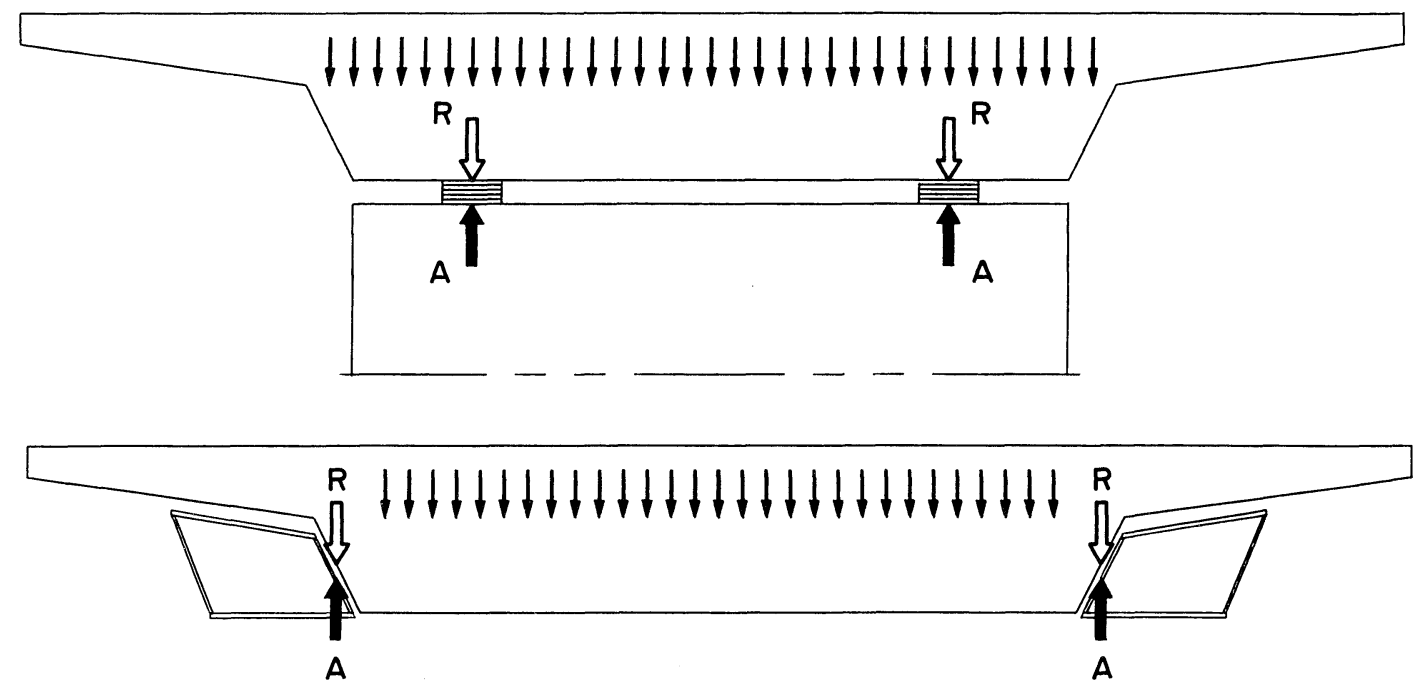

Fig. 6. Sustitución de reacciones de pila por reacciones de vigas.

\section{Descripción del mecanismo de transferencia de reacciones}

Consiste básicamente en sustituir las parejas de acciones y reacciones existentes entre el tablero de hormigón y las pilas a eliminar, por otras entre tablero y vigas metálicas actuando prácticamente en las mismas secciones transversales del puente, sin alterar la posición vertical del tablero en dichas secciones (Fig. 6).

Para lograr este objetivo se llevan a cabo dos operaciones sucesivas:

1. Puesta en carga de las vigas metálicas.

2. Acoplamiento vigas metálicas-tablero de hormigón.

\section{Puesta en carga de las vigas}

Esta operación se efectúa mediante un juego de dos dinteles de transferencia situados a ambos lados de cada pila a eliminar y lo más próximo posible a sus paramentos. Cada dintel incorpora dos gatos y dos marcos de suspensión colgados de la vigas (Fig. 7).

La gradual acción de los gatos - realizada de manera simultánea en ambas pilas a eliminar, para evitar los reajustes de fuerzas que se requerirían en cada grupo, caso de llevarse a cabo en operaciones sucesivas: primero en una pila y luego en otra- pone en carga las vigas metálicas y a la vez, paulatinamente, va reduciendo las mencionadas parejas de acciones y reacciones entre tablero de hormigón y pilas. Esta operación tan sólo produce ligeras deformaciones locales, al ir pasando las dos reacciones de cada pila a distribuirse entre los cuatro apoyos proporcionados por los gatos (Fig. 8).

Los movimientos de las vigas van anulando gradualmente las contraflechas geométricas previstas por el cálculo y realizadas en taller (Fig. 9), de manera que al alcanzarse el valor total de la transferencia de reacciones, los bordes inferiores del tablero de hormigón y las vigas metálicas coincidan prácticamente.

La rigidez de dichas piezas metálicas se determina, precisamente, para conseguir esta circunstancia y en base a optimizar el canto de las vigas y lograr que se cumpla la condición $\mathrm{h}_{\mathrm{s}}+\mathrm{d} \approx \mathrm{h}_{\mathrm{C}}$.

En el instante teórico en que el conjunto de gatos de cada pila iguala las reacciones del tablero en las mismas se culmina esta primera fase.

Los valores reales de estas reacciones se midieron previamente en obra mediante gatos y flexímetros obteniéndose las curvas del diagrama fuerza-levantamiento que permite precisar dichos valores (Fig. 10) por el cruce de las dos ramas de los mismos: la inicial de meras deformaciones del sistema pilatablero y la final del proceso, ya prácticamente cinemático, de elevación. 


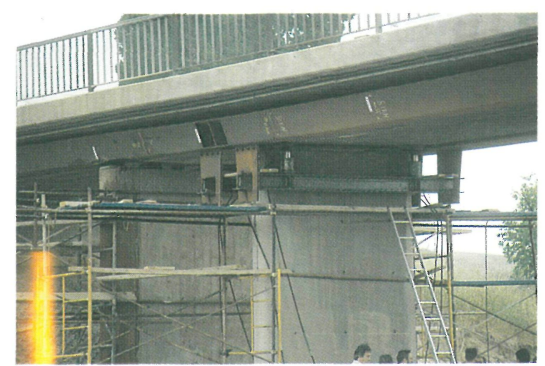

Detalle de la riga con el mecanismo de liansigerencia.

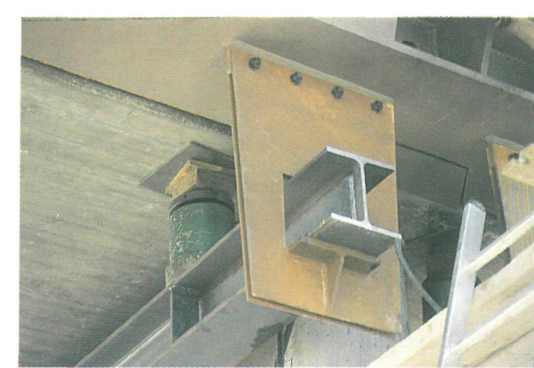

Iarco yerfil de transferencia con gates.

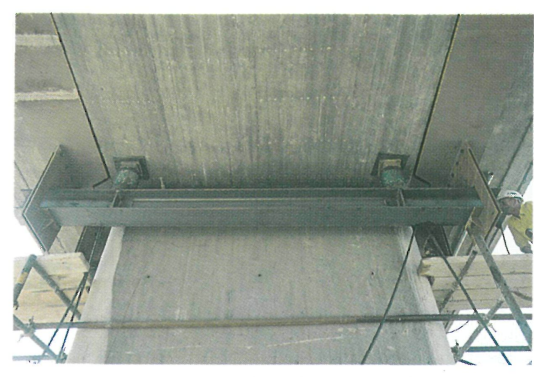

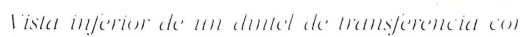
los gatos.

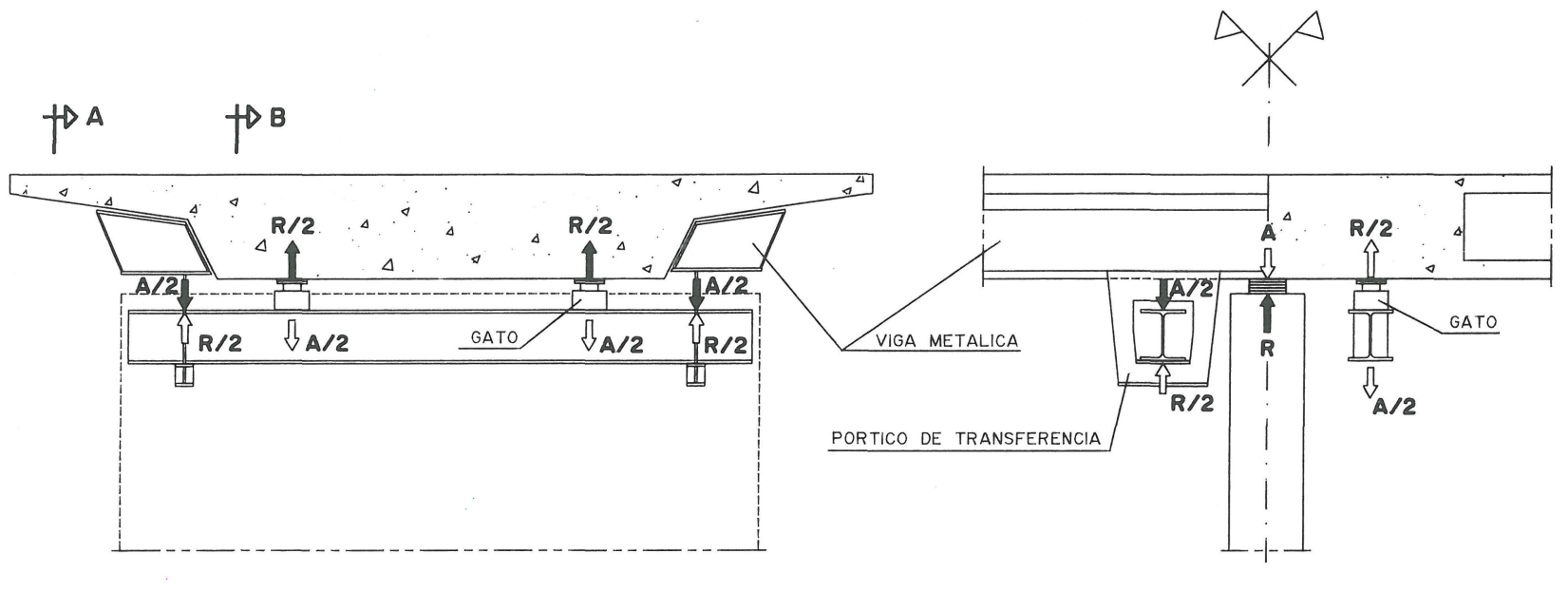

$\rightarrow A A \quad t D B$

SEMISECCION A - A SEMISECCION B - B

Fig. 7. P'uesta en carga de las vigas melálicas.
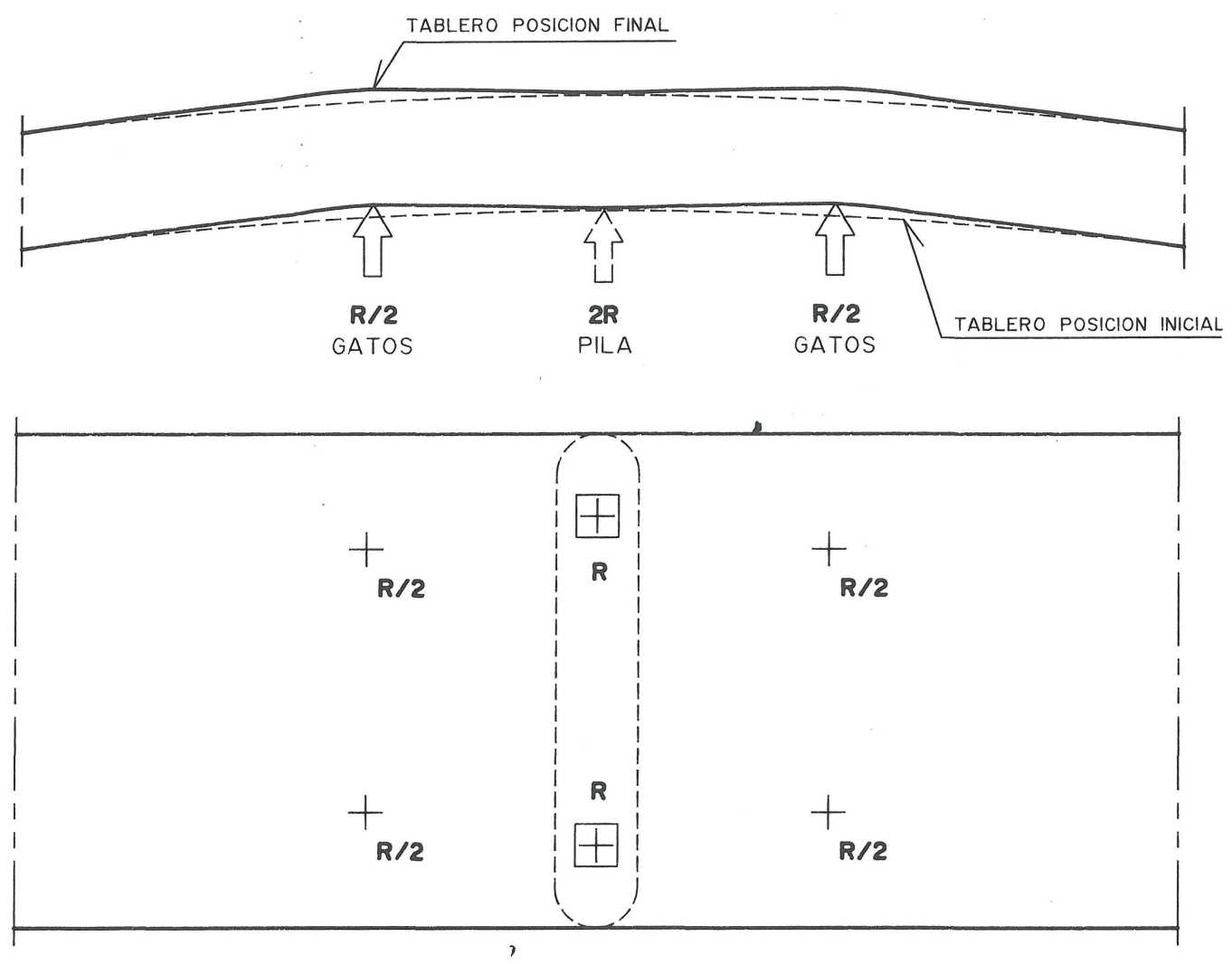

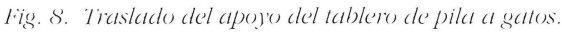

(c) Consejo Superior de Investigaciones Científicas 

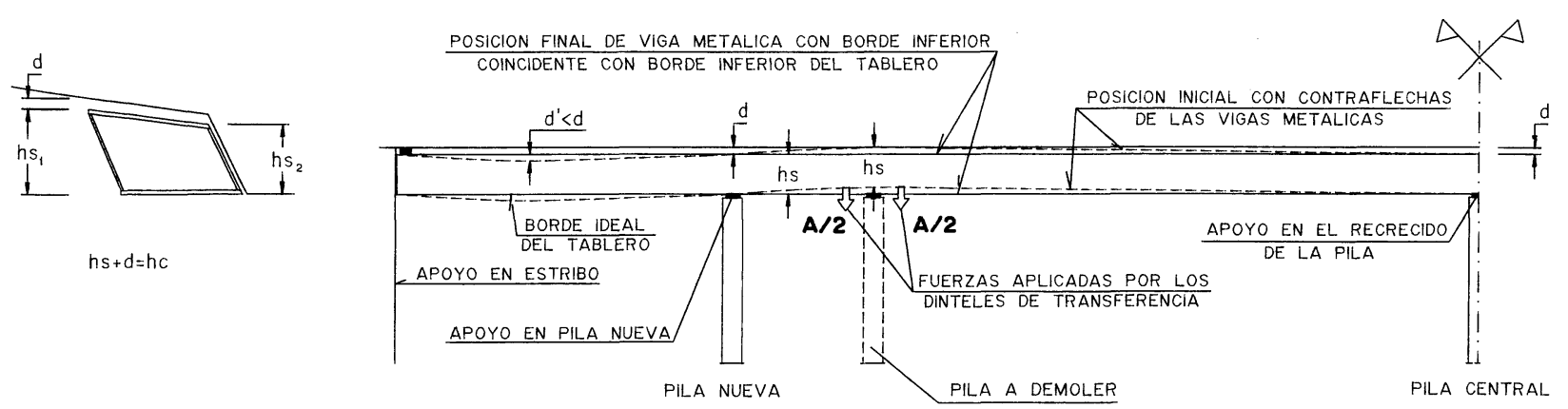

Fig. 9. Disposición de contraflechas y posición final después de la puesta en carga de las vigas metálicas.

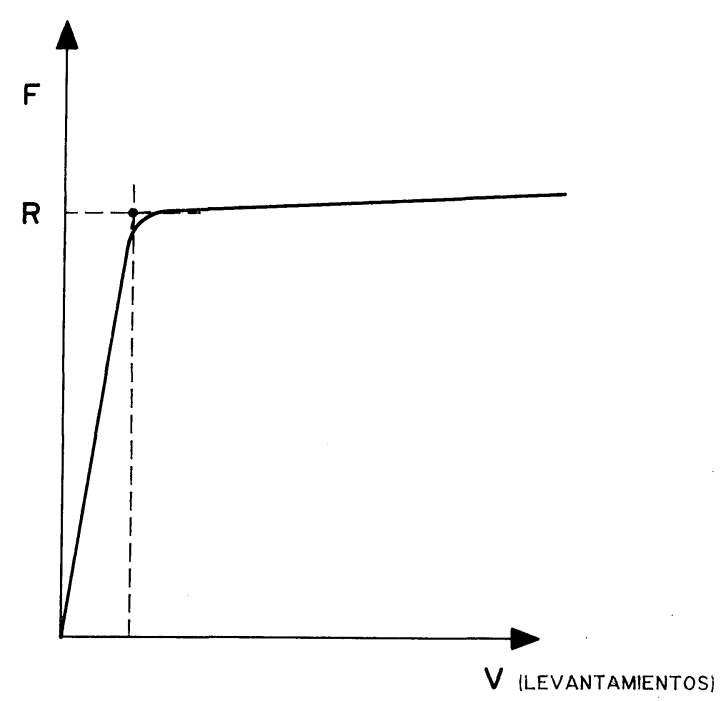

Fig. 10. Diagramas de fuerzas-levantamientos en pilas existentes

Debe tenerse en cuenta que, debido a los pegamentos empleados en los apoyos, la presencia de lechada y las adherencias parásitas de carácter físico-químico producidas entre apoyos y tablero con el paso del tiempo, los valores ideales de las reacciones quedan desvirtuados si se quieren definir risualizando el instante de la separación del tablero respecto a sus apoyos.

En general, se consideraron para las reacciones a transferir los valores definidos por dichos ensayos de control pero ligeramente mayorados, de manera de llegar a percibir visualmente los primeros indicios de despegue; pero en algunas ocasiones, dependiendo de las cargas y capacidades de transferencia, se adoptaron estrictamente los valores ideales medidos. Incluso en un caso en el que las reacciones medidas fueron notablemente superiores a las previstas por el cálculo en el proyecto, se adoptaron valores ligeramente inferiores para limitar las flechas de las piezas metálicas a valores próximos a los previstos en dicho cálculo, dando lugar a un leve reparto de la reacción total permanente entre ambos sistemas: vigas metálicas y tablero de hormigón.

Debe decirse que salvo en el caso citado, en el que el valor de la reacción superaba ampliamente el valor teórico deducido del análisis actualizado de los tableros existentes, debido a la presencia parásita de barras pasantes en la zona de junta del estribo próximo, la coincidencia entre los valores del ensayo y los del cálculo de las antiguas estructuras fue muy ajustada.

\section{Acoplamiento vigas-tablero}

Alcanzada la puesta en carga final de las vigas, que coincide idealmente con la anulación de las reacciones sobre las pilas a eliminar, se lleva a cabo un pretensado transversal dispuesto en los ejes de dichas pilas que acopla lateralmente las vigas metálicas y el tablero de hormigón. Inmediatamente después de esta operación se eliminan los apoyos del tablero en dichas pilas y se procede a descargar los gatos. 

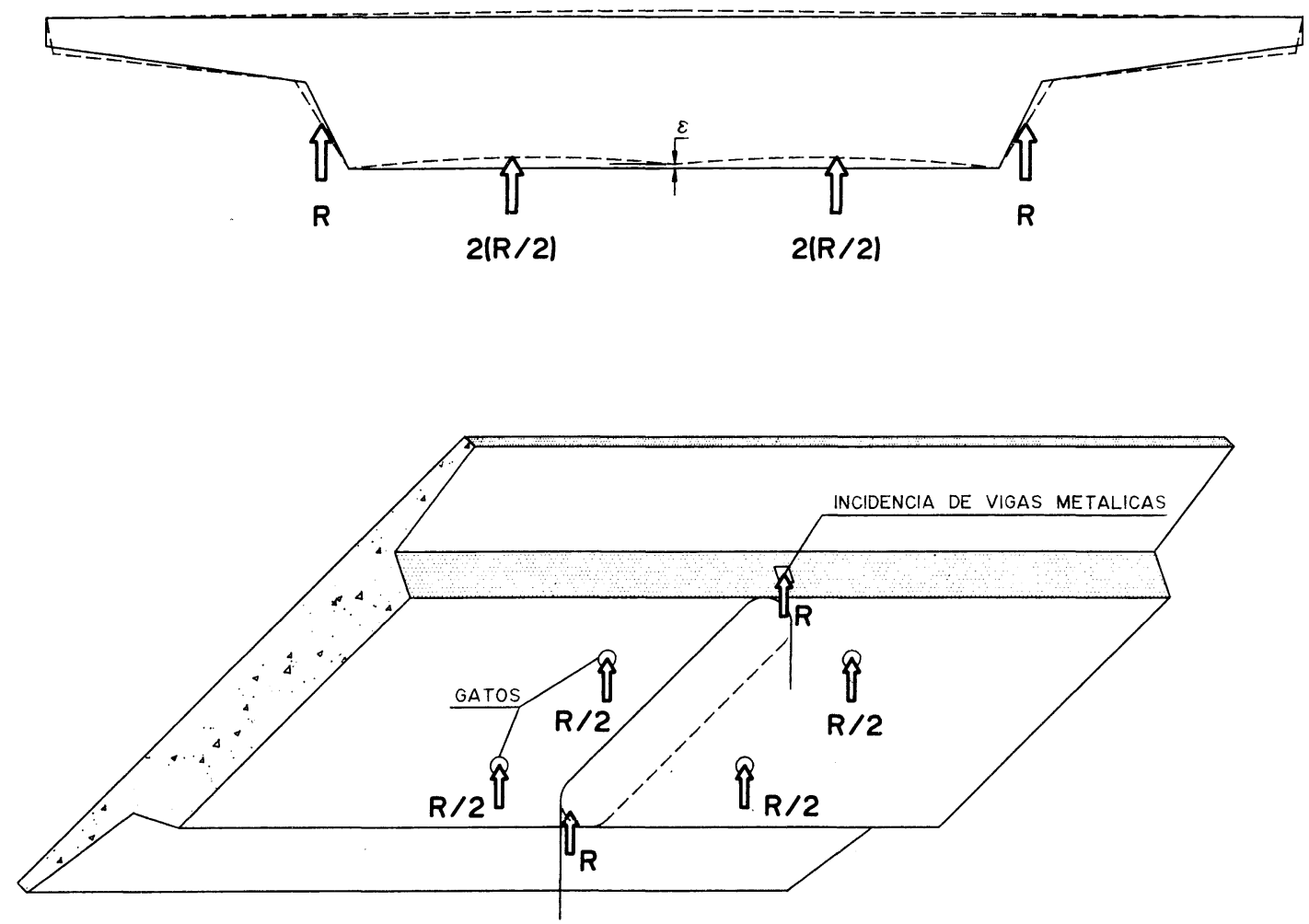

Fig. 11. Redistribución local de fuerzas en equilibrio durante la descarga de gatos.

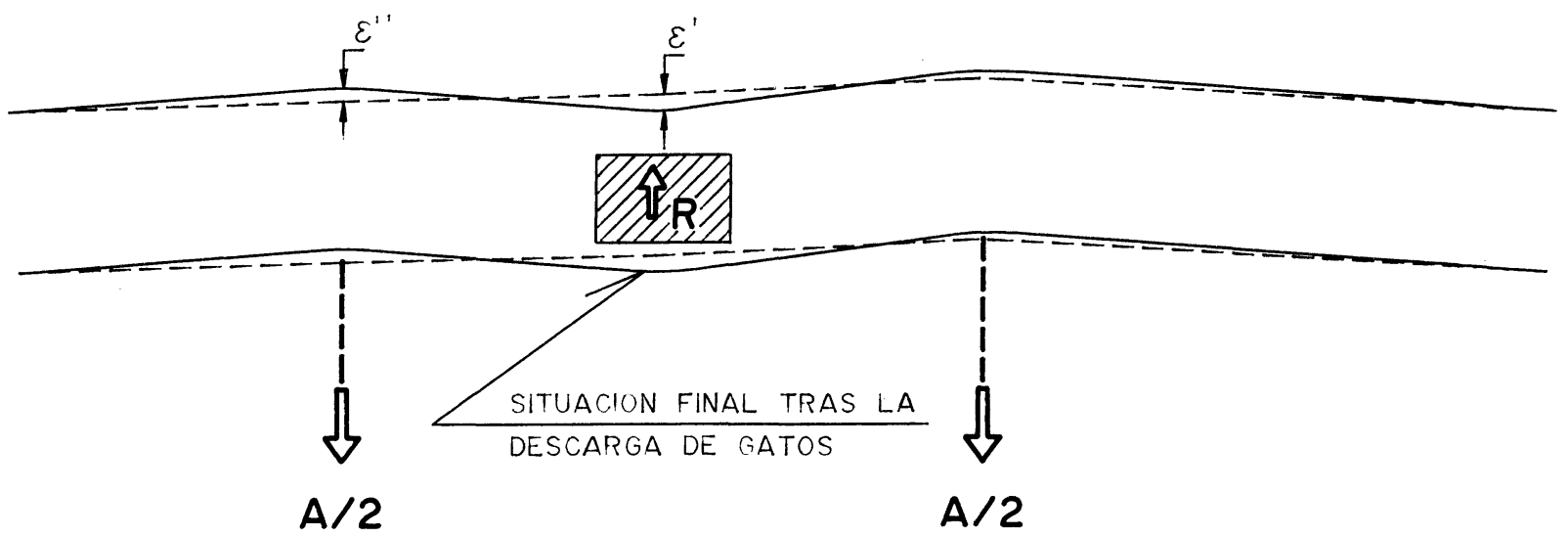

Fig. 12. Redistribución local de fuerzas en equilibrio durante la descarga de gatos y transferencia de reacciones a las vigas.

Esta actuación provoca una redistribución local de las fuerzas en equilibrio, tanto en el hormigón, al pasar las fuerzas que actuaban sobre los gatos a situarse en los puntos de contacto con las vigas metálicas (Fig. 11), como en las piezas de acero al desplazarse las reacciones sobre los marcos de suspensión a actuar como acciones hacia arriba en dichos puntos de contacto (Fig. 12). Todo ello provoca deformaciones locales de carácter mínimo en ambos sistemas pero sin modificación ninguna de las deformadas existentes en ambos sistemas y, consiguientemente, de los esfuerzos y del resto de las reacciones de los diferentes apoyos.

Las uniones vigas-tablero se llevan a cabo mediante un potente pretensado transversal dispuesto en los ejes de las pilas a demoler, realizado mediante parejas de barras en la mayor parte de los casos (solamente en una ocasión se emplearon cables) por sus favorables condiciones de colocación, muy 

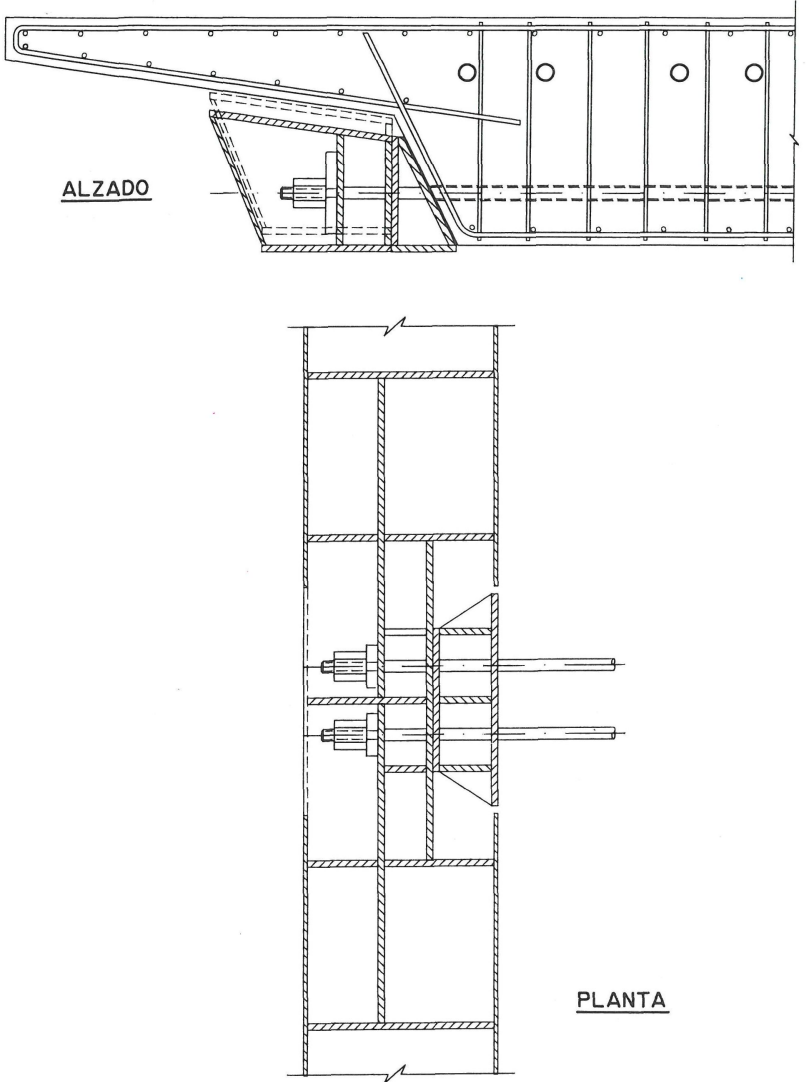

Fig. 13. Disposición del pretensado en las secciones de vigas y tablero.

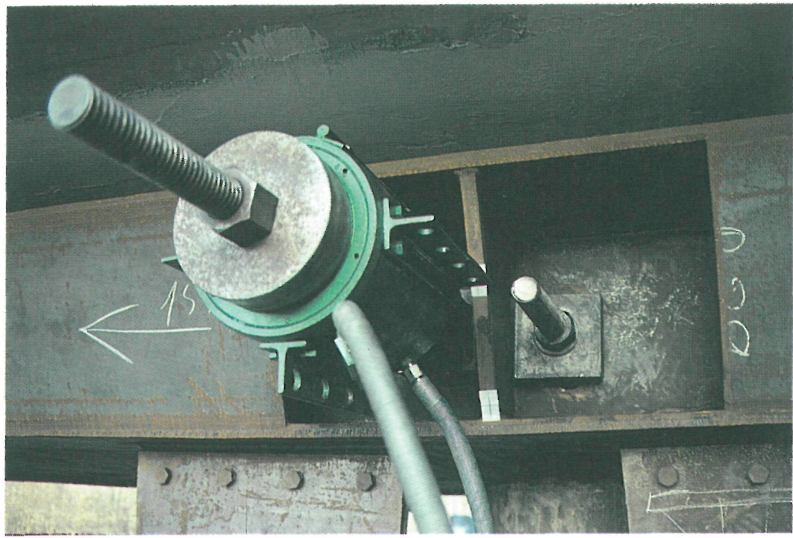

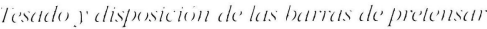

pequeñas pérdidas de enclavamiento (aspecto importante dadas las relativamente cortas longitudes de tesado), protección, etc. Estas barras se situaban en el interior de perforaciones realizadas en el tablero en la zona de macizados sobre pilas y centradas sobre la parte inferior del canto, en donde no existía ningún problema de encuentro con las armaduras activas superiores, ni las pasivas inferio- res; y se anclaban a las vigas metálicas en el interior de las mismas, a través de unos elementos específicos de forma triangular denominados células. Para ello, se habían dejado ventanas provisionales en el alma exterior de las vigas, que al final de la operación se cerraban mediante soldeo, restituyéndose la continuidad de dichas caras exteriores de las vigas cajón metálicas (Fig. 13).

Estas células merecen una descripción algo pormenorizada por su importante papel en el proceso operativo.

En realidad, si los paramentos laterales del tablero hubieran sido verticales, como lo fueron en uno de los casos (Fig. 14), dichas células no hubieran sido necesarias, reduciéndose a meras chapas de reparto del pretensado, y despegue del hormigón para absorber las irregularidades del sistema de hormigón. El rozamiento entre vigas y tablero provocado por las fuerzas del pretensado transversal sería el efecto que permitiría la transferencia de reacciones mediante la conocida condición $\mathrm{P}_{\mathrm{o}} \mu>\mathrm{R}_{1}$.

Sin embargo, la disposición inclinada de tales caras da lugar a una complejidad y condiciones muy diferentes.

En principio, se podría pensar incluso en no llevar a cabo el pretensado sino que el propio efecto de las acciones del tablero sobre las vigas metálicas, a través de las caras inclinadas, produciría el efecto de la puesta en tensión de las barras. Sin embargo, en este caso, los alargamientos producidos en las mismas por esta circunstancia darían lugar a un descenso del tablero (Fig. 15) y, consiguientemente, una importante redistribución de los esfuerzos existentes en el mismo bajo las cargas permanentes, en oposición a lo requerido. Por esta circunstancia el pretensado transversal se hace preciso.

Por otra parte, si no se dispusieran células, al producirse la puesta en carga de las vigas las superficies laterales internas de las mismas, inicialmente en contacto con las almas de hormigón, se separarían apreciablemente del mismo (Fig. 16) requiriendo fuertes incrementos de pretensado para anular esta separación, provocando momentos transversales en las piezas y desfavorables acciones en los apoyos de neopreno, marcos de suspensión, etc.; en suma, dificultando fuertemente el proceso de acopladura por tesado. Las piezas célula proporcionan la superficie de contacto vertical necesaria entre ambos sistemas para posibilitar la acopladura por tesado sin ningún tipo de problemas (Fig. 17). 


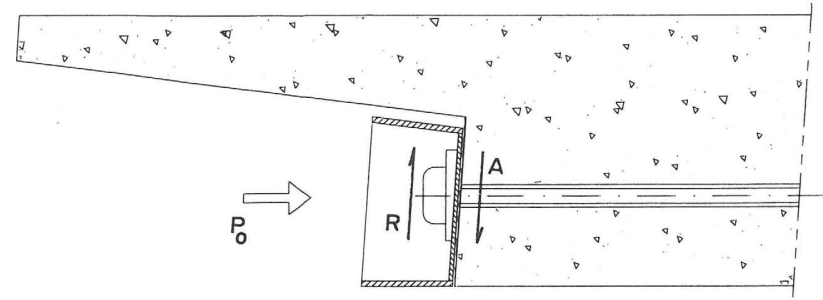

Fig. 14 .

Paso especial doble con paredes verticales del tablero de bormigón.
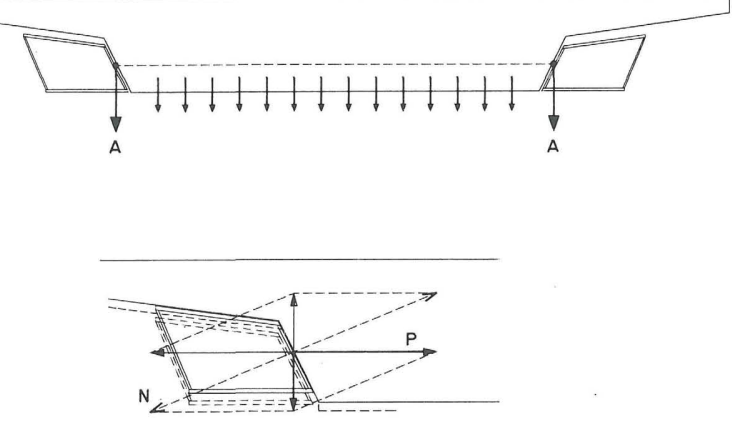

Fig. 15. Movimientos del tablero por aplicación pasiva de la carga del tablero sobre las vigas.
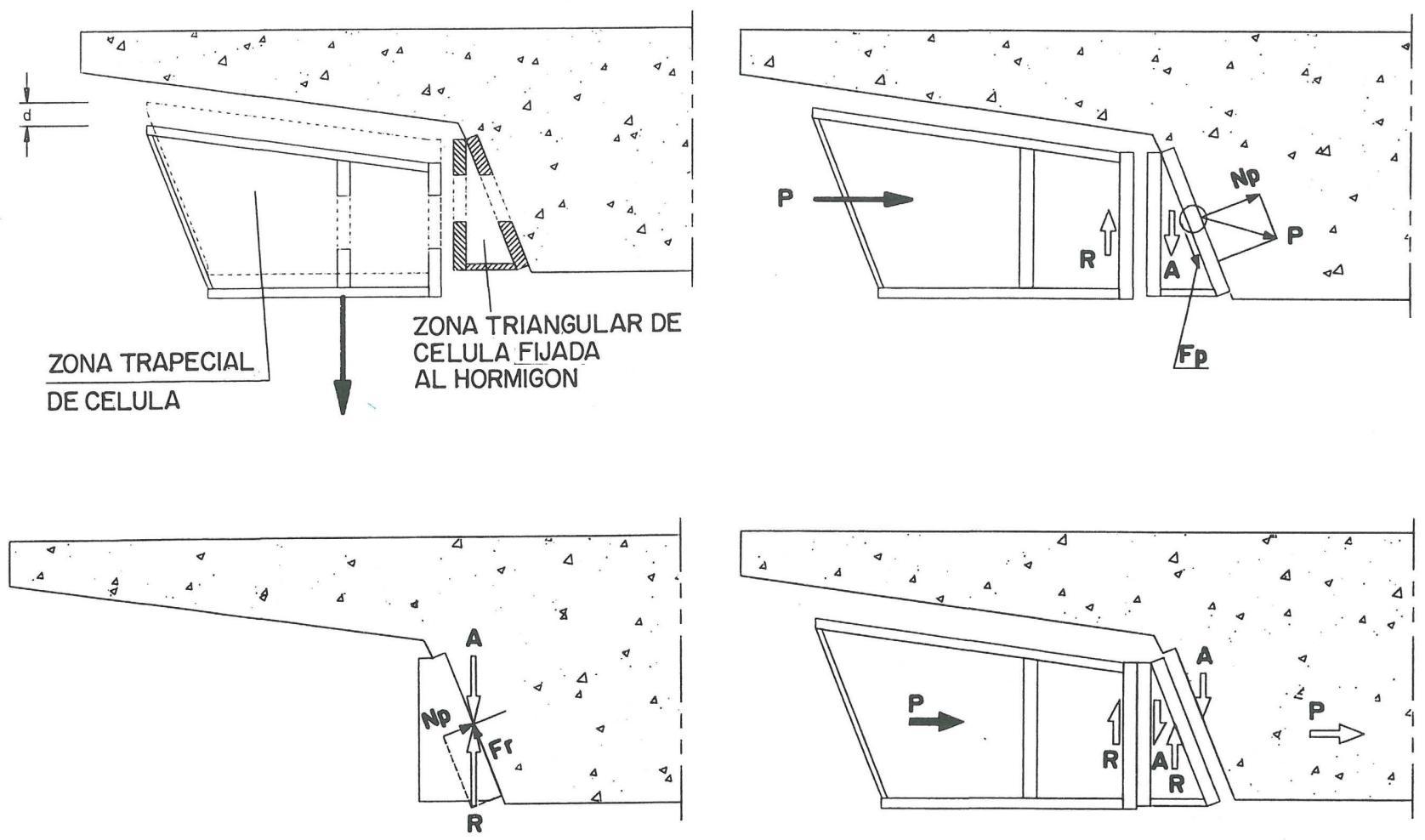

Fig. 17. Esquema de funcionamiento y fuerzas en las células. 
En los pasos esviados, las células se hacen espaciales para acoplar su cara interna al esviaje y a la inclinación de las almas permitiendo realizar el tesado siguiendo la dirección de la pilas. Asimismo, cada célula se desdobla en dos cuerpos para limitar la zona de incidencia con las vigas metálicas (Fig. 18).
Sin embargo, la presencia de las células —o mejor aún, el hecho de la existencia de los planos inclinados que dan lugar a su inclusión- determina que durante el tesado se producen en las superficies de contacto con el hormigón esfuerzos rasantes muy importantes. Aunque las tensiones tangenciales producidas por estos esfuerzos vienen acompañadas

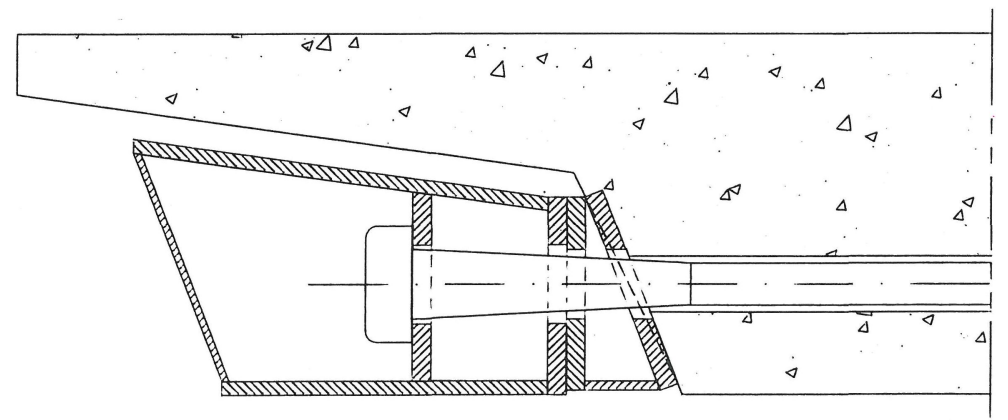

SECCION A - A

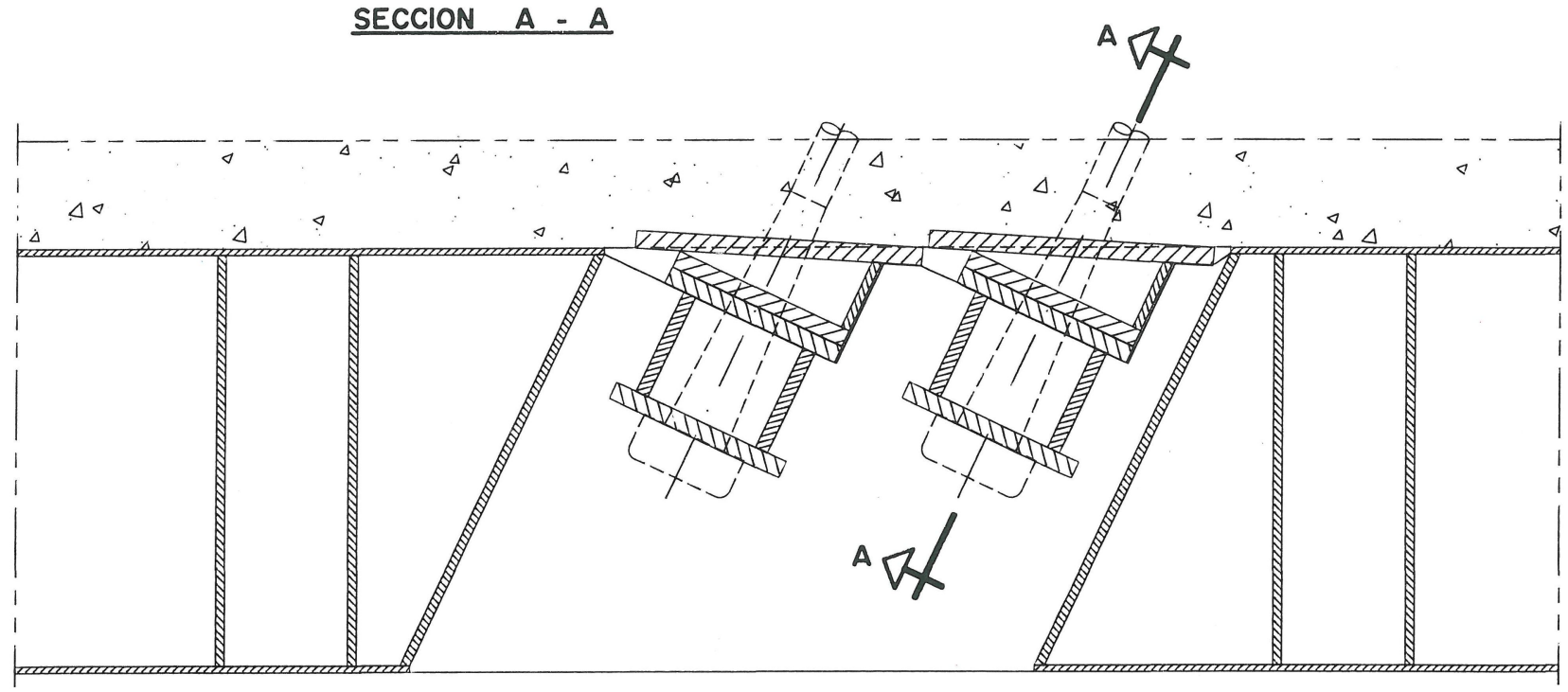

Fig. 18. Células en vigas de puentes esviados.

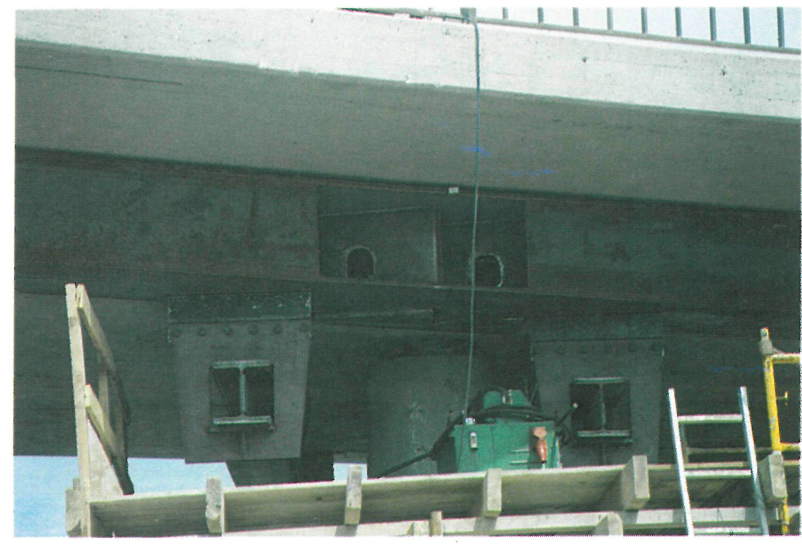

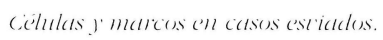

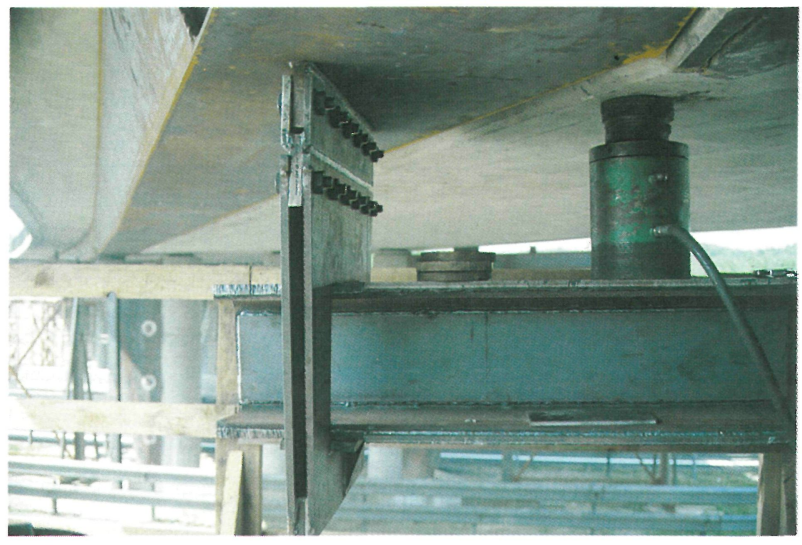

Disposicion de mareos de transferencia en casos estiados. 
por favorables tensiones normales concomitantes provocadas por dicho pretensado, resulta adecuado tratar de reducir la incidencia de dichas tensiones tangenciales.

Para ello, como la posterior descarga de los gatos de transferencia da lugar a la introducción de fuer- zas ascendentes en las superficies de contacto células-tablero que producen rasantes en dichas superficies de signo opuesto a las inducidas por el pretensado, se adoptó la precaución de llevar a cabo el tesado y la posterior descarga de gatos, no en una sola fase, sino en tres escalones: en primer lugar, se aplicaba un tercio del tesado total previsto, seguido

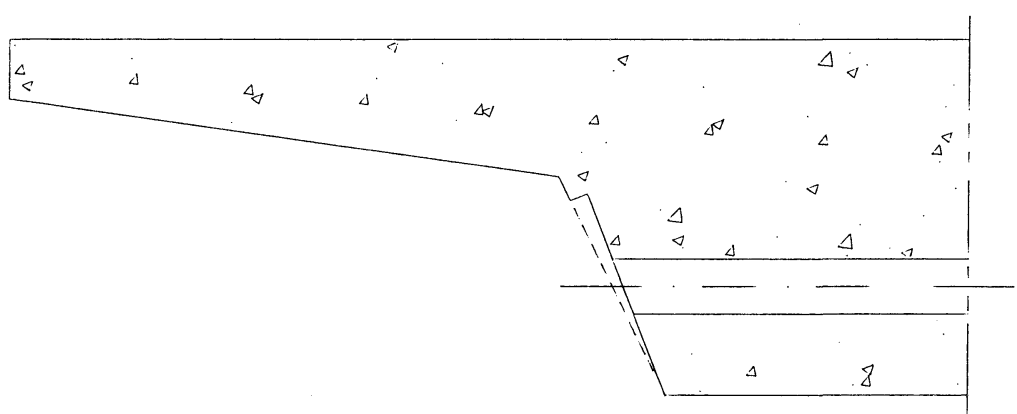

SECCION A - A

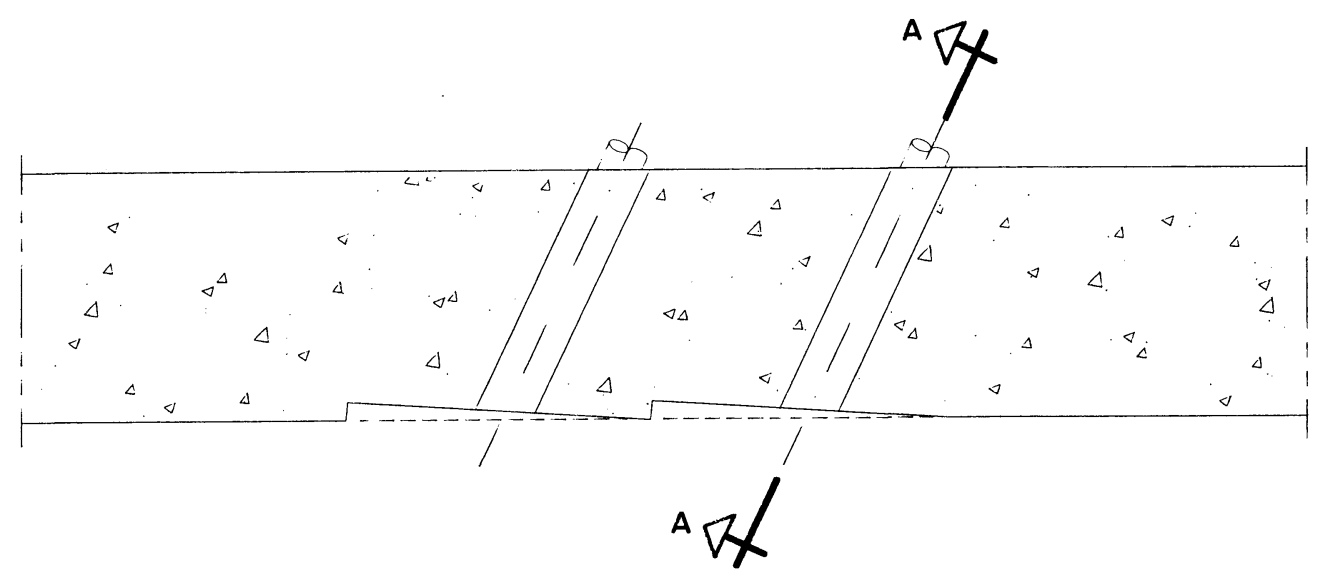

Fig. 19. Picado de bordes para favorecer la aplicación del tesado en los pasos esviados.
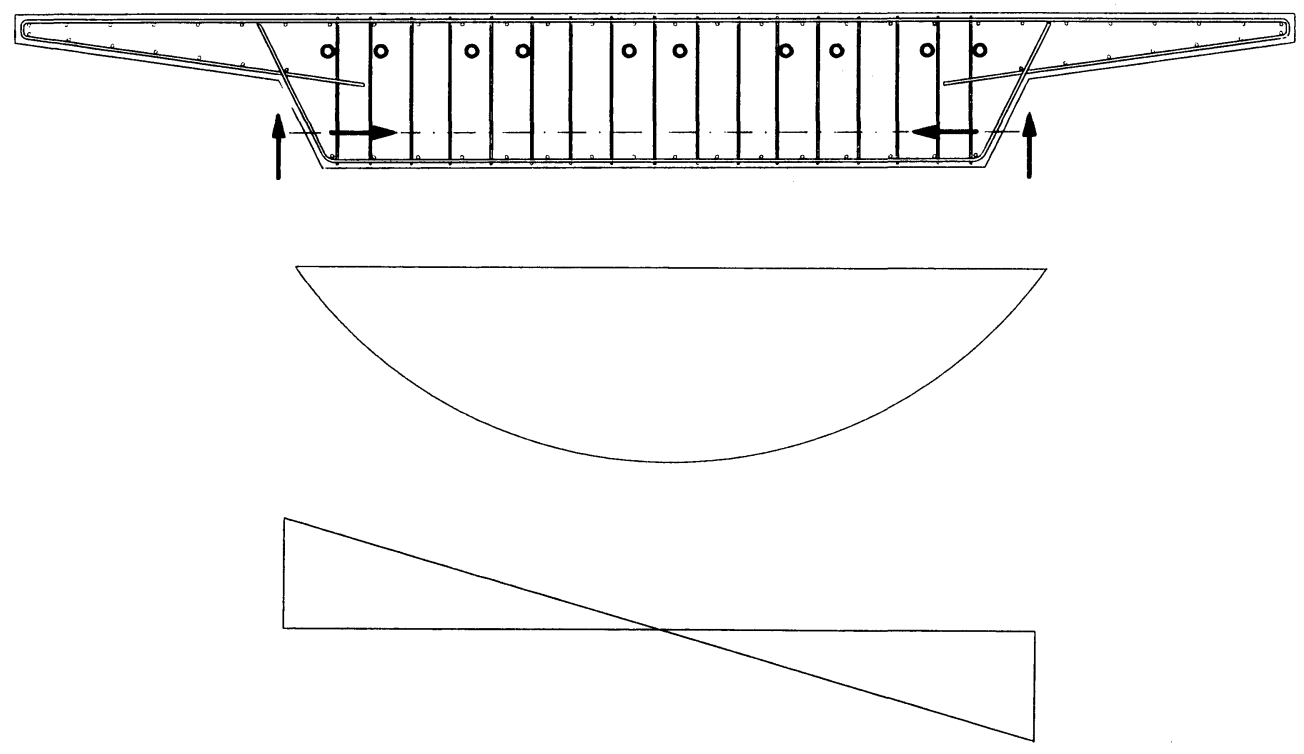

Fig. 20. Viga dintel transtersal en tablero para traslado de cargas a las vigas. 


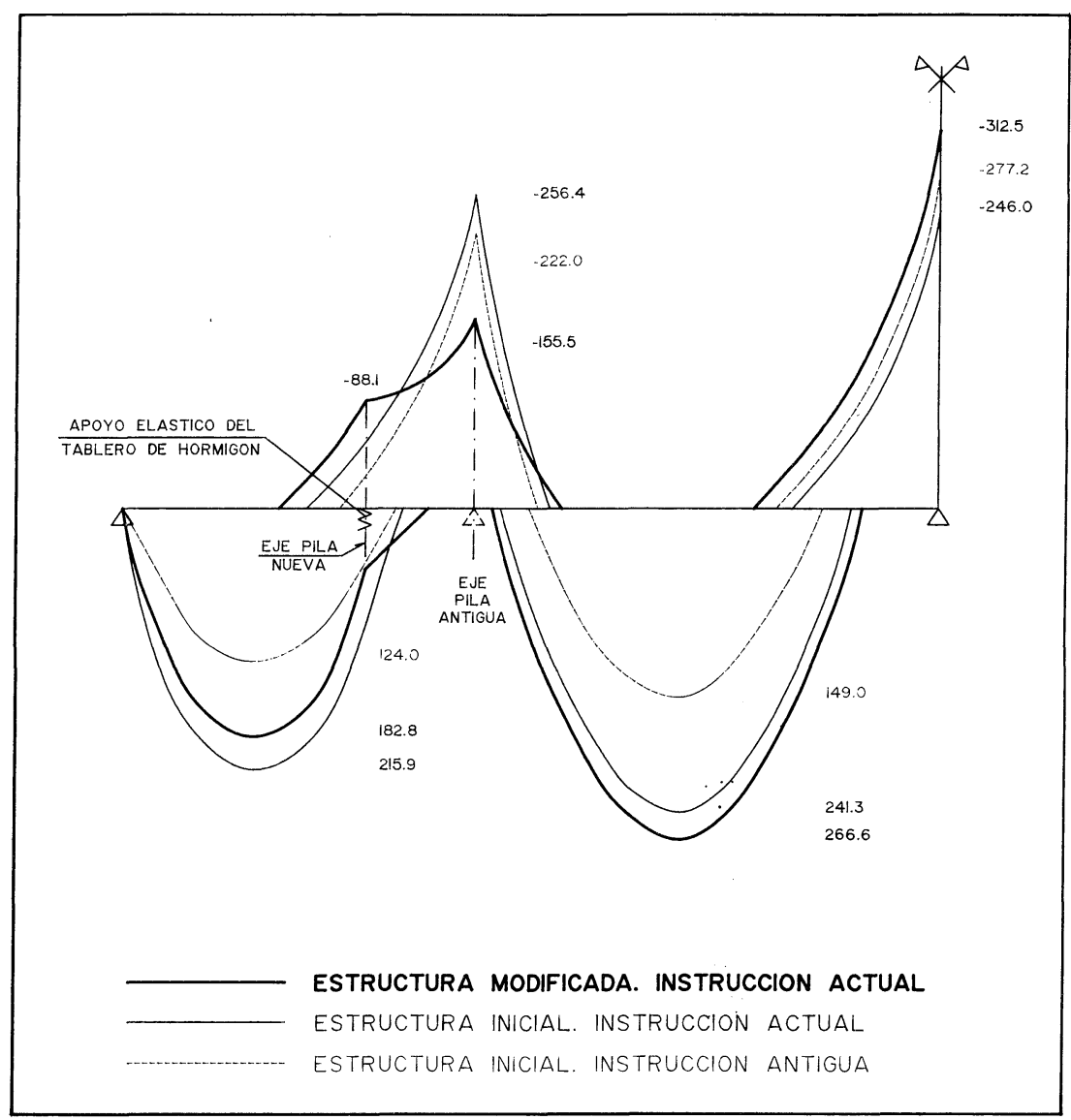

Fig. 21. Envolvente de esfuerzos en el tablero de hormigón de un paso tipo.

de una descarga de gatos de un tercio del total de la reacción asumida por los mismos; y así sucesivamente hasta llegar al tesado final seguido de la total descarga de los gatos. De hecho, incrementando el número de escalones de carga se podría llegar a valores de $\tau$ tan pequeños como se quisiera. El escalonamiento adoptado fue decidido en base a que con esta subdivisión se alcanzaban en las superficies de contacto células-hormigón valores de $\tau \approx 14,5 \mathrm{kp} / \mathrm{cm}^{2}$.

En los ensayos realizados con los mismos productos, proporciones y procesos de aplicación realizados en obra se obtuvieron valores ideales de rotura a flexotracción $\sigma=15,5 \mathrm{~kg} / \mathrm{cm}^{2}$ y $\tau=18 \mathrm{kp} / \mathrm{cm}^{2}$ en el instante de rotura. Dada la presencia de las acciones normales de compresión antes citadas, se consideraron perfectamente apropiados los valores adoptados, y el proceso en todos los casos respondió con total corrección.

En las células esviadas se adoptó la precaución adicional de un picado con profundidad variable de la superficie, para reducir el ángulo de desvío horizontal de $\mathrm{P}_{\mathrm{O}}$ y favorecer la calidad de la unión célula-hormigón (Fig. 19).

Finalmente, debe señalarse que el pretensado transversal nò sólo cumple la fundamental misión de lograr una adecuada transferencia de reacciones, como ha quedado expuesto, sino que permite que los esfuerzos producidos en la viga dintel transversal de hormigón que se crea entre cada pareja de puntos de acopladura (Fig. 20), pueden ser resistidos por el tablero sin producirse la rotura transversal del mismo, al no contarse con armaduras pasivas importantes en dicho elemento y, de hecho, en varios de los pasos de mayor anchura los esfuerzos de pretensado fueron determinados por esta condición y no por la transferencia. Asimismo, la profundidad del punto de aplicación debió ser mantenida lo más baja posible para favorecer este trabajo.

El pretensado es, por consiguiente, una operación de máxima y múltiple importancia, básica para el correcto funcionamiento del proceso. 


\section{Sobrecargas de uso}

Terminada la transferencia se efectúa el apoyo del tablero de hormigón en las nuevas pilas y el conjunto completo pasa a resistir las acciones de las sobrecargas con la condición de iguales flechas en los puntos de acopladura.

Debido a la gran diferencia de rigideces entre el tablero de hormigón y las vigas metálicas $(\approx 9$ a 1 ) la mayor parte de estas acciones serían absorbidas por aquél, generándose momentos negativos importantes en las secciones de apoyo del tablero de hormigón en la nuevas pilas y ligeros incrementos en los momentos de vanos y pila central (Fig. 21). En estos dos últimos casos los esfuerzos son resistidos sin problemas con tensiones máximas de tracción en servicio de $15 \mathrm{kp} / \mathrm{cm}^{2}$ en vanos y $12 \mathrm{kp} / \mathrm{cm}^{2}$ en pila central.

Sin embargo, en las secciones sobre las pilas nuevas no se podrían lograr condiciones análogas. Por ello en lugar de disponer apoyos rígidos entre el tablero de hormigón y las nuevas pilas se colocaron apoyos elásticos, formados por neopreno no zunchado de gran altura, situado en el interior de cajeados adecuados para controlar las condiciones de pandeo, y subdivididos en elementos para permitir su eventual sustitución futura, mediante extracción y reposición sucesiva de tales elementos (Fig. 22).

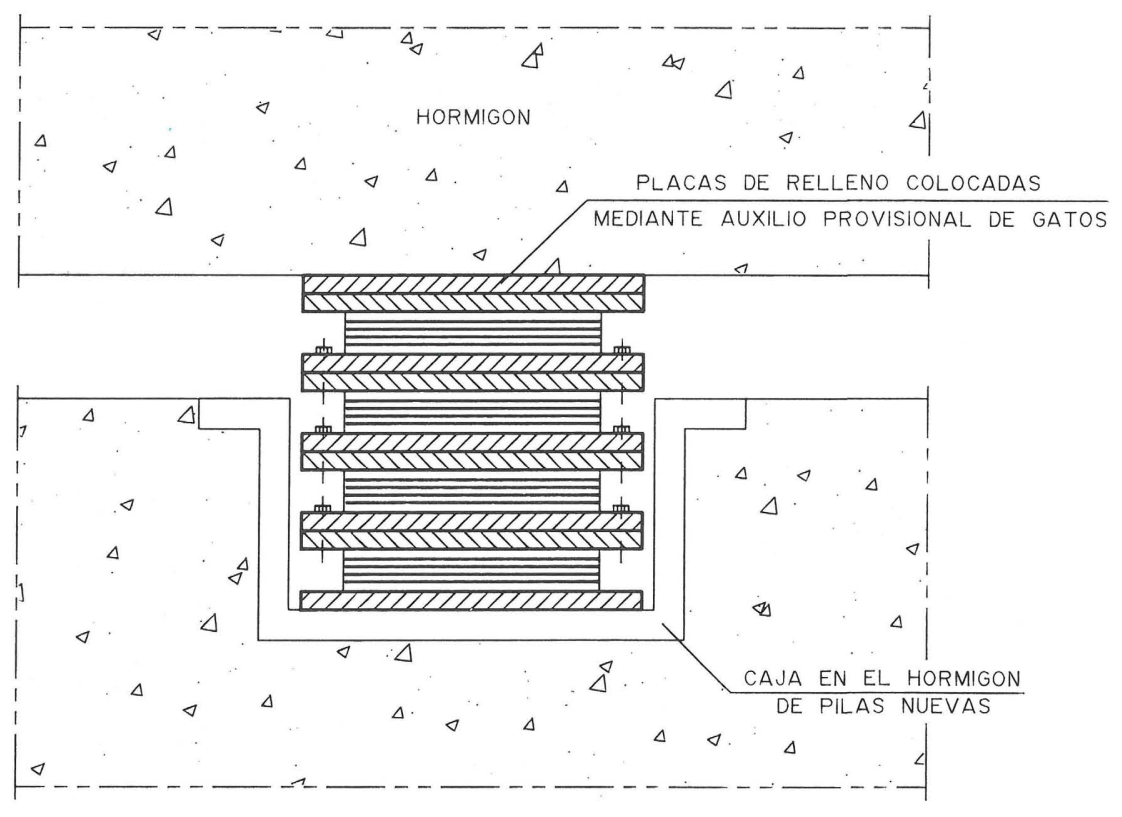

Fig. 22. Apoyos elásticos del tablero en las pilas nuevas.

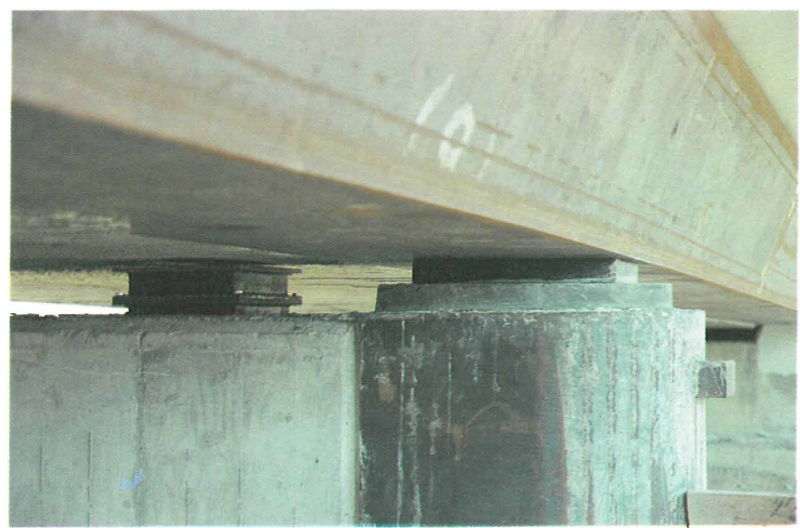

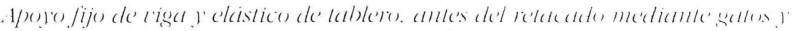
placas.

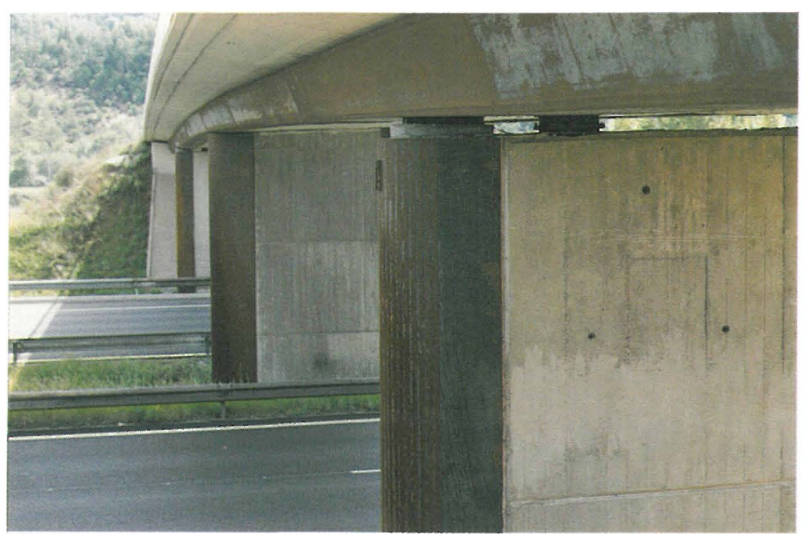

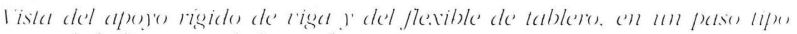
antes de la limpieza al chorro de arena. 


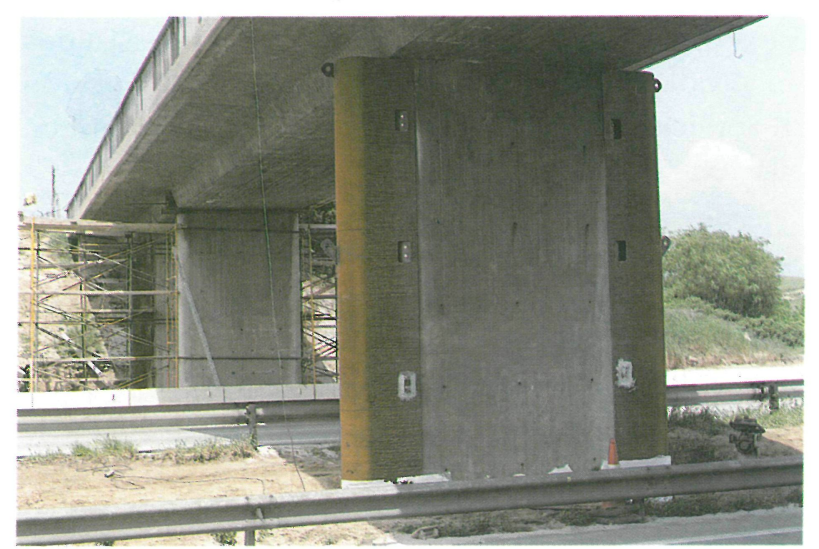

Fijaciones de los elementos acoplados a la pila central de las piezas en acero autorresistente a la corrosión.

Detalle de extremo con fijación al estribo; posteriormente sc suelda ligeramente una chapa de cierre y protección, en el fond de la viga.

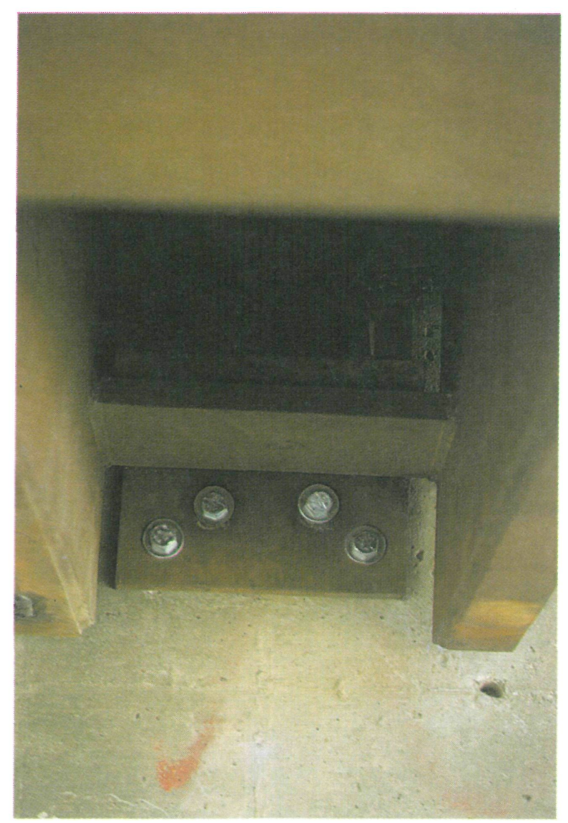

\section{Otros aspectos dell proceso}

El sistema de dinteles adicionales metálicos acoplados al tablero de hormigón se completa en las pilas por un acoplamiento semejante de elementos metálicos en este caso redondeados como lo son las pilas iniciales, que van simplemente adosados en el caso de la pila central, y formando cuerpo con el hormigón en las nuevas pilas intermedias (Fig. 3). De esta manera, el sobreancho total del conjunto de la estructura queda formalizado por dos bandas completas corridas en acero tipo CORTEN, que dan lugar a un aligeramiento visual del conjunto, y a una gran personalización de las estructuras, evitando el efecto de pesadez y monotonía de este tipo tan repetido de estructuras de hormigón.

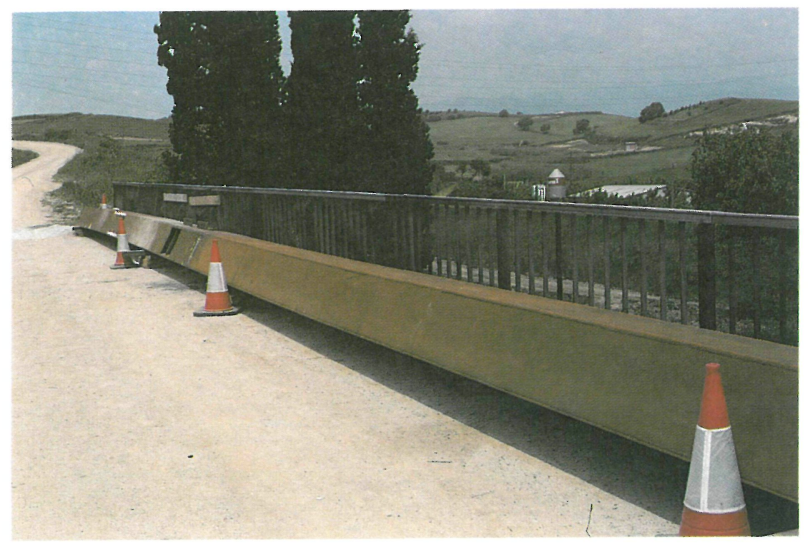

Ensamblaje en obra de una viga.
En los estribos, las vigas metálicas se apoyan mediante elementos directamente fijados con tornillos tipo HILTI a los tabiques frontales, y se mejora su garantía de respuesta frente a las acciones ascendentes, con la inserción de bloques de neopreno entre las vigas metálicas y los voladizos del tablero (Fig. 4).

\section{Proceso constructivo}

Tal y como se requería, la ejecución de las estructuras se produjo sin afectar prácticamente a los tráficos, con las mínimas interrupciones de seguridad, frente a posible despiste de conductores, en el instante de posicionamiento de las grandes vigas metálicas; piezas previamente conformadas en unidades

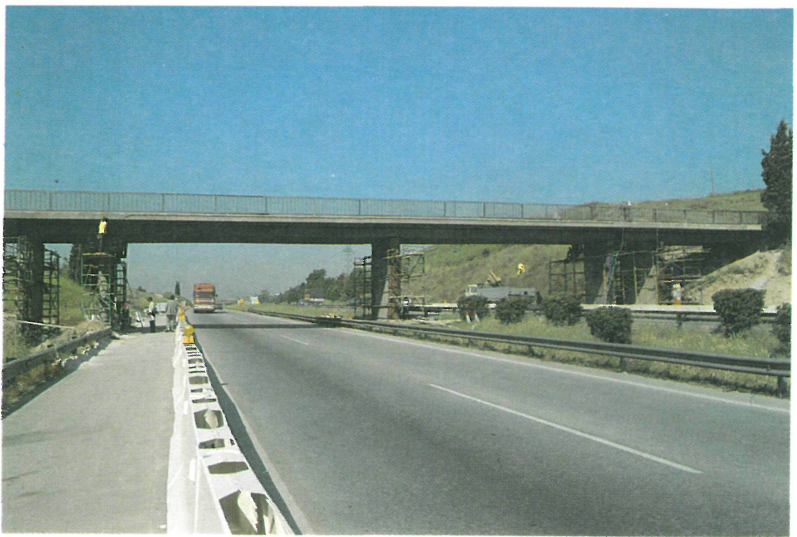

Disposición general de la zona de trabajo en an paso lipo. 


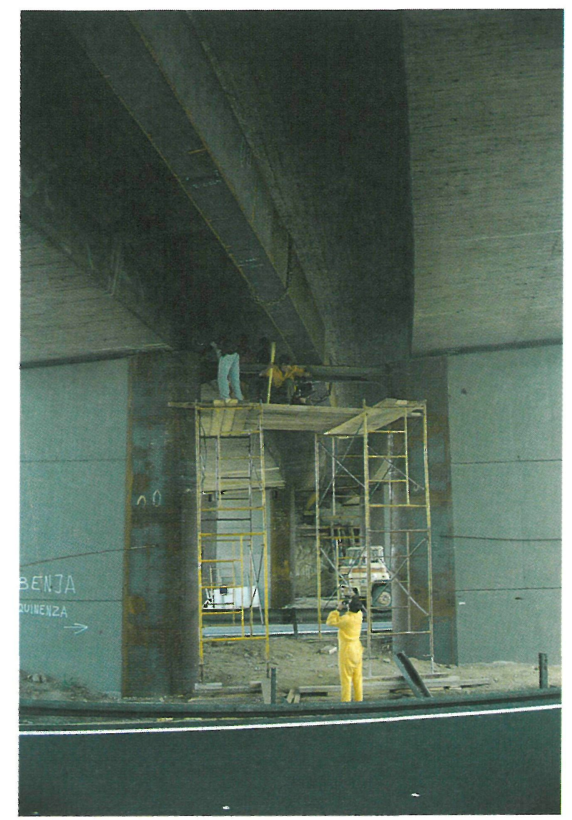

Colocación y ensamble de viga interior en paso especial doble.

totales mediante el soldeo, en las aceras de los pasos elevados, de los tres trozos ejecutados en taller. Dicho posicionamiento se lleva a cabo depositando la viga, mediante dos grúas situadas en las zonas extremas de la autopista, sobre castilletes provistos de una rampas de teflón o rodillos que las llevan automáticamente hasta su posición de contacto con el hormigón, con la ayuda de pequeños trácteles fijados a las pilas.

Todo el resto de las operaciones se produce mediante actuaciones locales en las zonas de medianas y laterales, con acceso directo desde las aceras de los pasos superiores, y dotados de adecuadas protecciones y señalizaciones para mejorar la seguridad frente al despiste de un conductor.

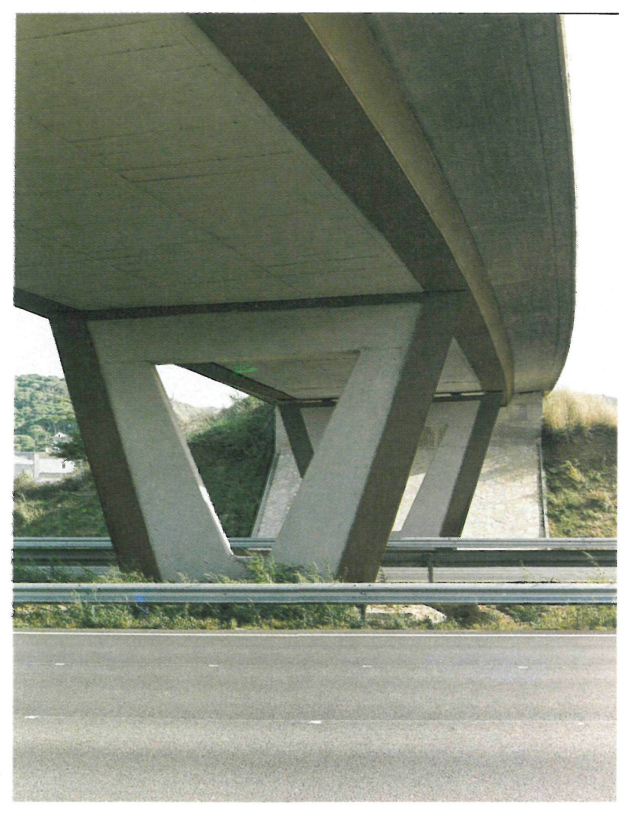

Pilas Nabla de un paso especial y curvo.

Un aspecto de la máxima importancia se centró en la precisión singularizada de las definiciones para la ejecución en taller de cada una de las vigas, realizada en base a la toma de datos de replanteo afinados del alzado longitudinal y transversal y angulaciones de las caras exteriores y voladizos de la losa de hormigón, ya que estos elementos presentaban variaciones muy aleatorias de bombeos, flechas, inclinaciones, etc. De esta manera se ajustaron al máximo las geometrías, intercalándose los apropiados espesores de chapa en la zona de células para evitar contactos parásitos de bombeo entre vigas y losa, y se ajustaron las contraflechas a los valores y datos reales definitivos, teniendo en consideración la reacciones exactas medidas previamente en las pilas a demoler.

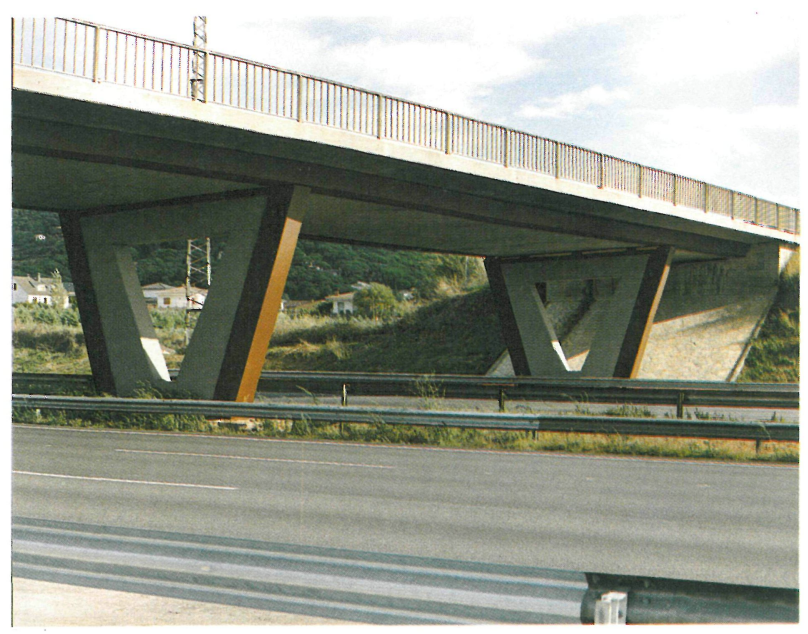

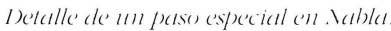

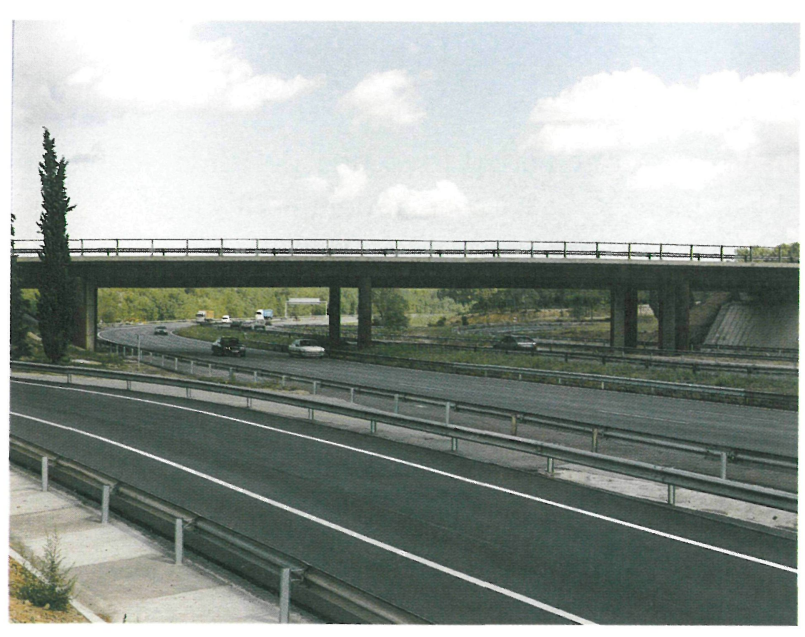

Aspectos de un paso especial doble curros. 


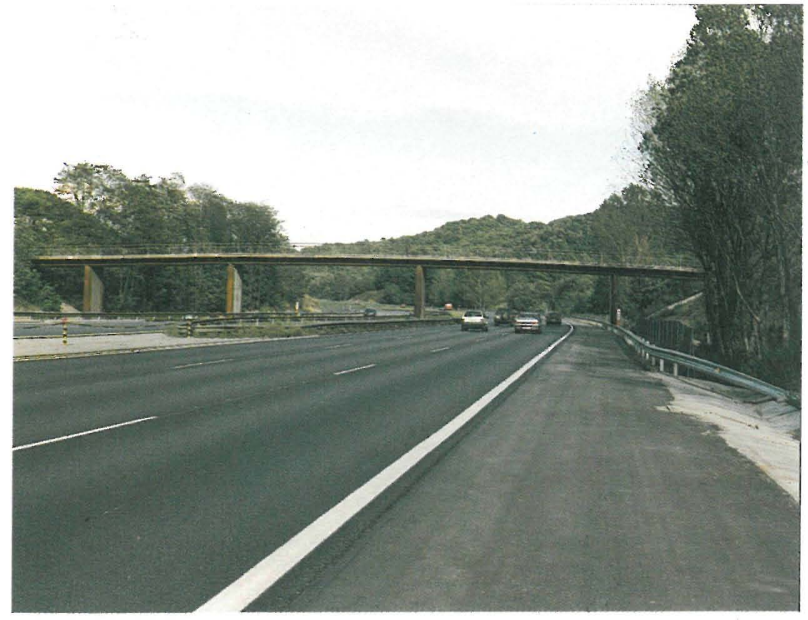

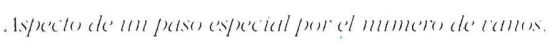

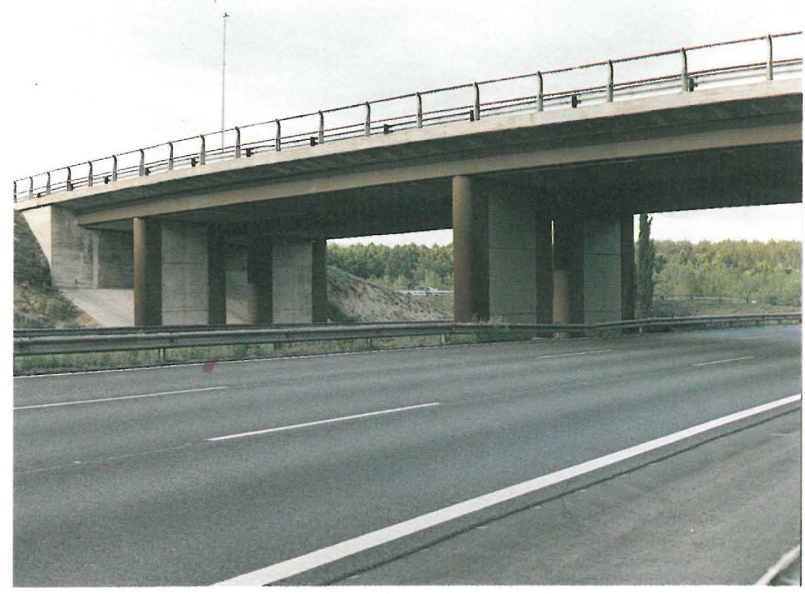

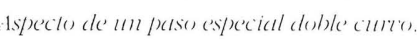

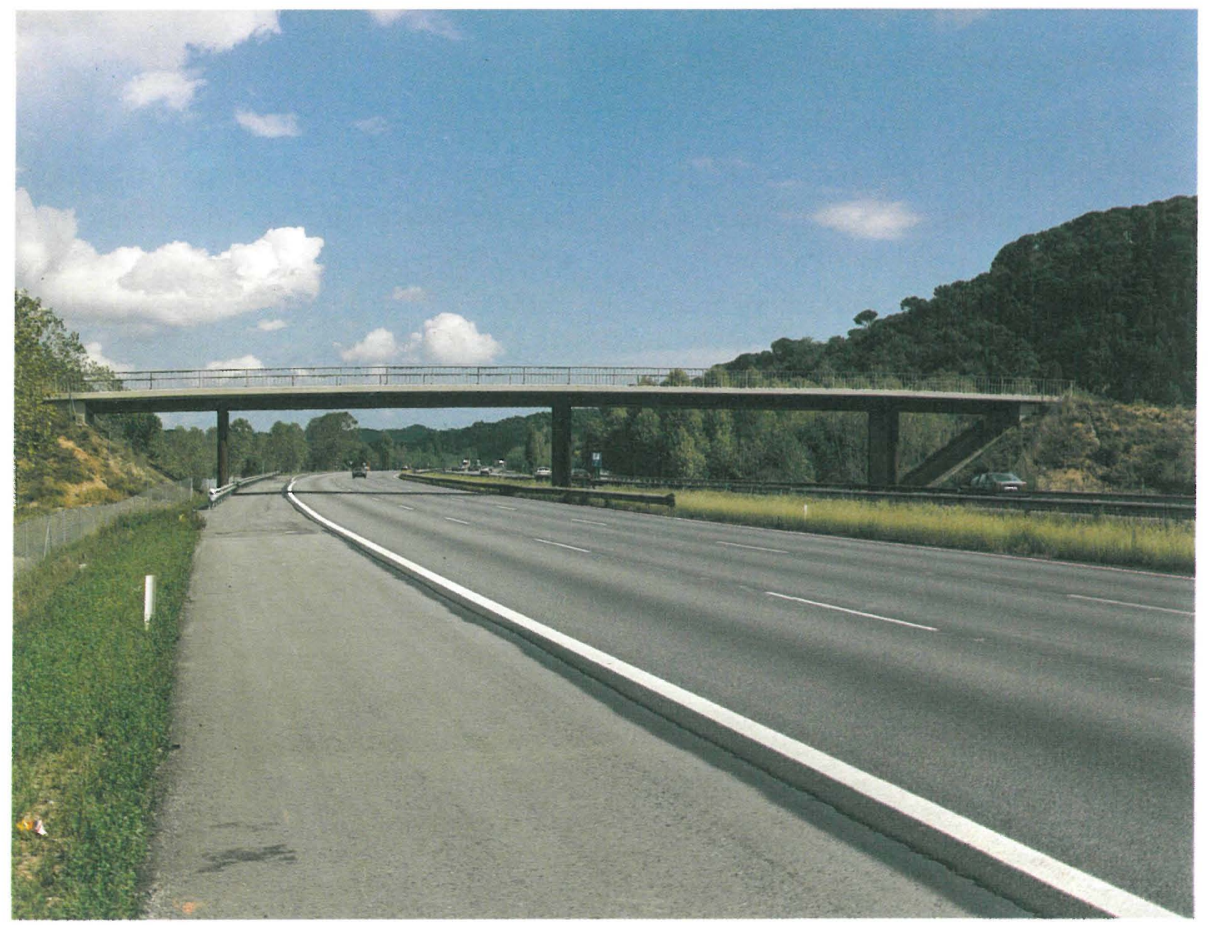

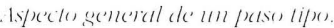

En toda esta actividad tuvo una decidida actuación el Gabinete IOC, y especialmente Nilo Lletjós, colaborador infatigable, así como los equipos de las tres empresas constructoras que llevaron a cabo los trabajos de realización: FOMENTO CC; OCP y HUARTE con una calidad y dedicación encomiables.

El proceso constructivo se inició, de acuerdo con una feliz decisión de ACESA, llevando a cabo inicialmente un sola obra, de tipo piloto, que permitió establecer de forma clara y precisa múltiples aspec- tos de tipo práctico y operativo a tener en cuenta y que dieron lugar a un documento de carácter de Pliego Complementario para el resto de las obras, lo cual permitió facilitar y sistematizar la realización del conjunto.

En los casos especiales: tramos curvos, pilas esviadas, cambios de anchuras y formas, etc., las soluciones adoptadas para el tablero fueron muy semejantes, con pequeñas variaciones de células o trazados; y en las pilas dieron lugar a nuevas disposiciones diferenciadas en base a las especiales características de sus 
formas y dimensiones. Tan sólo en el caso de la OF 47-7, al estar constituida por dos tableros paralelos en contacto, la incorporación de las vigas metálicas a las zonas interiores no accesibles superiormente, requirió el corte momentáneo de la autopista para situar mediante camiones los trozos de vigas en su posición en planta, elevándose de inmediato y sencillamente desde el tablero, a través de alveolos realizados en el mismo. Los trozos de estas piezas fueron soldados in situ en las zonas de pilas, pero ya sin afectar al tráfico al estar situados en el interior del hueco entre voladizos y vigas de hormigón.

Finalmente, unas palabras de agradecimiento a los equipos de control: TEC4 e INTECASA perso- nalizados en sus técnicos César Salvá, Antonio Santolaria y Miguel Angel Castillo, respectivamente; y a la propiedad en las personas de: F. Criado, J. V. Solano; F. Serralta, L. Lanzarote, Chordá, Del Pozo, etc. que animaron e impulsaron en todo momento el desarrollo del proyecto y la ejecución de las obras. En todas estas personas y en otras muchas anónimas está realmente la posibilidad de haber podido llevar a cabo las obras realizadas.

El coste global de las soluciones fue de 480 millones de pesetas, con una repercusión total de 76.200 $\mathrm{ptas} / \mathrm{m}^{2}$ de tablero, por debajo de cualquier posible solución de reposición o nueva obra.

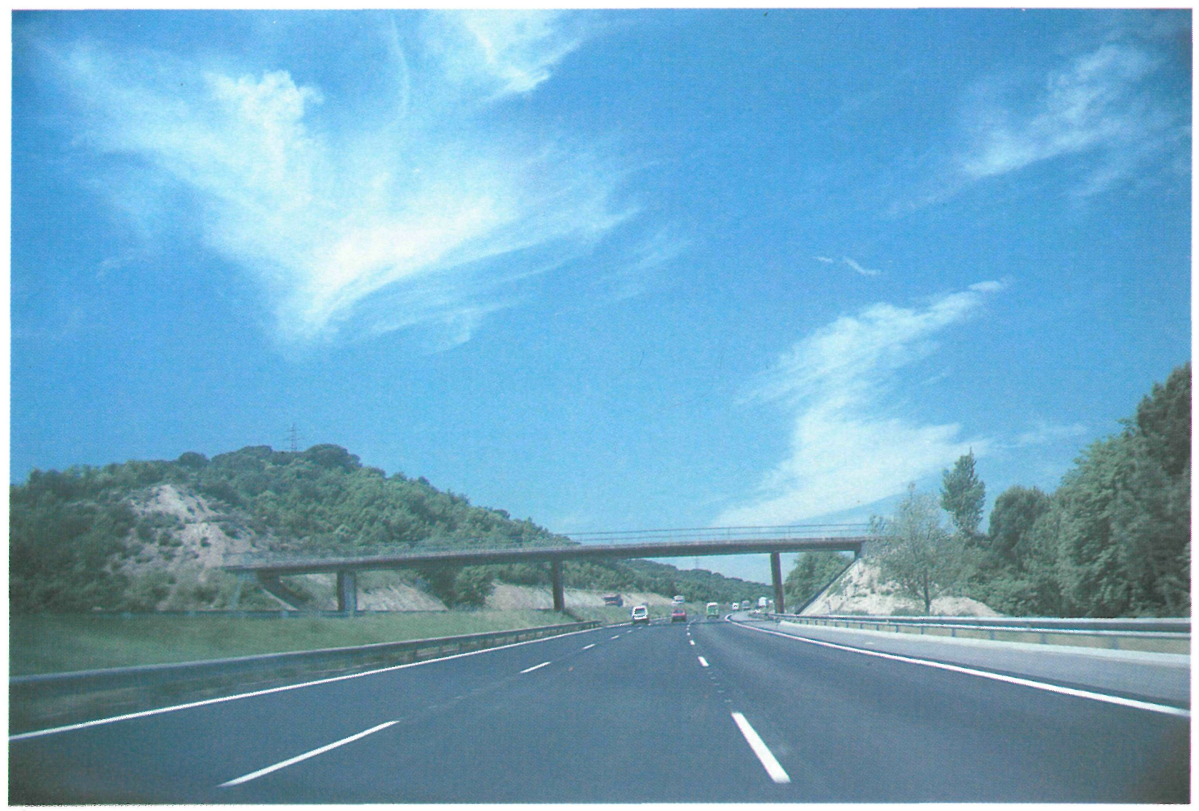

I tislas genereal

\section{Ficha técnica}

\begin{tabular}{|c|c|c|c|}
\hline Proyecto: & Julio Martínez Calzón (MC-2 Estudio de Ingeniería). & $\begin{array}{l}\text { Barras, gatos, pretensado } \\
\text { y elementos de pretensado }\end{array}$ & \\
\hline \multirow{2}{*}{ Dirección de obra: } & \multirow{2}{*}{ J. Martínez Calzón y Nilo Lletiós (IOC). } & y elevación: & CTT. \\
\hline & & Perforación: & PERFOR (1), FREPER (13). \\
\hline Contratistas: & FOMENTO CC (1 Paso), OCP (8), HUARTE (5). & Supervisión ACESA: & $\begin{array}{l}\text { F. Criado, J. V. Solano, F. Serralta, L. Lanzarote, } \\
\text { Sr. Chordá, Sr. Del Pozo }\end{array}$ \\
\hline Control de Obra: & TEC4, INTECASA. & Acero Tipo CORTEN $650 \mathrm{t}$ & Equivalente $102 \mathrm{~kg} / \mathrm{m}^{2}$ tablero. \\
\hline Estructuras metálicas: & URSSA (1), PLAIN (8), TALLER HUARTE (5), & Armaduras de pretensar $4 \mathrm{t}$ & Equivalente $0,64 \mathrm{~kg} / \mathrm{m}^{2}$ tablero. \\
\hline
\end{tabular}

